Alberto Azoubel Antunes

\title{
O papel dos genes do pepsinogênio $C(P G C)$ e do antígeno de membrana específico da próstata (PSMA) no diagnóstico do câncer da próstata
}

Tese apresentada à Faculdade de Medicina da Universidade de São Paulo para obtenção de título de Doutor em Ciências

Área de concentração: Urologia

Orientador: Prof. Dr. Miguel Srougi

São Paulo

2008 
Dados Internacionais de Catalogação na Publicação (CIP)

Preparada pela Biblioteca da

Faculdade de Medicina da Universidade de São Paulo

Oreprodução autorizada pelo autor

Antunes, Alberto Azoubel

O papel dos genes do pepsinogênico $\mathrm{C}(P G C)$ e do antígeno de membrana específico da próstata (PSMA) no diagnóstico do câncer da próstata / Alberto Azoubel Antunes. -- São Paulo, 2008.

Tese(doutorado)--Faculdade de Medicina da Universidade de São Paulo. Departamento de Cirurgia.

Área de concentração: Urologia.

Orientador: Miguel Srougi.

Descritores: 1.Próstata 2.Neoplasias prostáticas/diagnóstico 3.Biópsia 4.Expressão gênica

USP/FM/SBD-326/08 


\section{Dedicatória}

À Antonio Pessoa Antunes e Mabel Azoubel Antunes, por sua eterna abnegação e amor. A quem peço desculpas pelos longos períodos de ausência que a vida me obriga. 


\section{Agradecimentos}

Ao Professor Miguel Srougi, a quem minha admiração e respeito não podem mais ser descritas em palavras. Mais do que pela oportunidade de defender esta tese de doutoramento sob sua orientação na Universidade de São Paulo, agradeço pela confiança, ensinamentos e pela paciência em tolerar minhas limitações no convívio diário. Poder conviver com o professor Miguel e sua equipe já constitui o maior título de minha carreira.

À Dra. Kátia Ramos Moreira Leite, que me abriu as portas de seu laboratório para realização deste trabalho. Idealizadora deste projeto, seu conhecimento e dedicação à patologia clínica e molecular a tornam uma profissional completa. Poder trabalhar com a Dra. Kátia é um privilégio.

À Dra. Juliana Moreira de Sousa Canavez, sem a qual este trabalho não teria sido realizado. Responsável direta pela realização de todos os experimentos foi para mim uma grata surpresa nesta caminhada. Sempre disponível e prestativa, além de altamente qualificada.

Ao Dr. Marcos Francisco Dall'Oglio, pela amizade verdadeira e companheirismo durante todos estes anos em São Paulo. Seu otimismo, perseverança, sensibilidade e força de trabalho o tornam um profissional exemplar. 
À Sabrina Thalita dos Reis e Fabíola Elizabeth Villanova pela paciência em me ensinar os princípios básicos da biologia molecular. 
Esta tese está de acordo com as seguintes normas, em vigor no momento desta publicação:

Universidade de São Paulo. Faculdade de Medicina. Serviço de Biblioteca e Documentação. Guia de apresentação de dissertações, teses e monografias. Elaborado por Anneliese Carneiro da Cunha, Maria Julia de A. L. Freddi, Maria F. Crestana, Marinalva de Souza Aragão, Suely Campos Cardoso, Valéria Vilhena. $2^{\mathrm{a}}$ ed, São Paulo: Serviço de Biblioteca e Documentação; 2005

Referências: adaptado de International Committe of Medical Journals Editors (Vancouver)

Abreviaturas dos títulos dos periódicos de acordo com List of Journals Indexed in Index Medicus. 


\section{Sumário}

Lista de abreviaturas, símbolos e siglas

Lista de figuras

Lista de tabelas

Resumo

Summary

1. Introdução 1

2. Objetivos 8

3. Métodos 10

3.1 Pacientes e amostras tumorais 11

3.2. Exame Anátomo-patológico 18

3.2.1 Exame Macroscópico 18

3.2.2 Exame Microscópico 19

3.3. Processamento da amostra 20

3.4. Extração de RNA e síntese de cDNA 20

3.5. qRT-PCR e Expressão gênica 22

3.6. Análise Estatística 23

4. Resultados 25

5. Discussão 32

6. Conclusões 43

7. Referências 45 


\section{Lista de Abreviaturas}

Cap - Câncer de Próstata

PSA - Antígeno Prostático Específico

HPB - Hiperplasia Prostática Benigna

\%PSAL/PSAT - Razão do PSA livre pelo PSA total

DPSA - Densidade do PSA

BTRUS - Biópsia Transretal da próstata guiada por Ultra-som

PSCA - Prostate stem cell antigen

AMACR - Alfa-metilacil coenzima A racemase

GSTP1- Glutationa S-transferase P1

PSMA - Prostate- specific membrane antigen

TMEFF2 - TransMembrane protein with EGF-like and two Follistatin-like domains 2

GREB1 - Gene regulated by estrogen in breast cancer

TH1L - Trihydrophobin Human-Like 1

IGH3 - Immunoglobulin heavy chain, gamma polypeptide

$P G C$ - progastricsin (pepsinogen C)

$B 2 M$ - beta-2-microglobulin

qRT-PCR - Reação em cadeia da polimerase quantitativa em tempo real 


\section{Lista de Figuras}

Figura 1 - Tecido maligno de paciente com Cap 12

Figura 2 - Tecido prostático de paciente com HPB 14

Figura 3 - Tecido normal de paciente com Cap 16

Figura 4 - Expressão quantitativa da $B 2 M$ de acordo com os tecidos analisados 26

Figura 5 - Expressão quantitativa dos genes PSMA, TMEFF2, GREB1, TH1L, IGH3 e PGC no tecido do Cap em relação à HPB 27

Figura 6 - Box-plot da expressão do PGC de acordo com o estádio patológico 29

Figura 7 - Box-plot da expressão do PSMA de acordo com o estádio patológico 29

Figura 8 - Box-plot da expressão do PGC de acordo com o escore de Gleason 30

Figura 9 - Box-plot da expressão do PSMA de acordo com o escore de Gleason 30

Figura 10 - Padrão de expressão do PGC e PSMA no tecido benigno de pacientes com Cap em relação à HPB 31 


\section{Lista de Tabelas}

Tabela 1 - Identificadores dos genes analisados através da técnica de qRTPCR 11

Tabela 2 - Características dos 33 pacientes com Cap 13

Tabela 3 - Características dos nove pacientes com HPB 15

Tabela 4 - Características dos 17 pacientes com Cap cujo tecido benigno foi analisado 17

Tabela 5 - Expressão mediana dos seis genes estudados através do qRT-PCR nos 33 pacientes com Cap 28 


\section{RESUMO}

Antunes AA. O papel dos genes do pepsinogênio $C$ (PGC) e do antígeno de membrana específico da próstata (PSMA) no diagnóstico do câncer da próstata [tese]. São Paulo: Faculdade de Medicina, Universidade de São Paulo; 2008.

INTRODUÇÃO: O diagnóstico do câncer de próstata em pacientes com níveis séricos do antígeno prostático específico persistentemente elevados após biópsia prostática negativa representa um grande desafio para urologistas e patologistas. A baixa especificidade do antígeno prostático específico e a baixa sensibilidade da biópsia prostática guiada por ultra-som são os maiores obstáculos observados na prática clínica. Apesar do uso de diversos métodos para prever a presença de câncer na glândula, nenhum deles tem precisão absoluta, obrigando os pacientes a realizar novas biópsias. Neste contexto, a descoberta de novos marcadores diagnósticos para o câncer da próstata tornase necessária. OBJETIVO: Avaliar o valor diagnóstico da expressão de seis genes no tecido prostático de pacientes com câncer de próstata clinicamente localizado. MÉTODOS: O estudo consistiu na análise de 50 pacientes com diagnóstico de câncer da próstata, submetidos à prostatectomia radical por doença localizada. A seleção dos genes foi baseada em um estudo prévio que utilizou a tecnologia de microarray (Agilent Technologies 44k whole human genome, two-color) em pacientes com câncer de próstata, divididos de acordo com as características clínico-patológicas. Entre os 4.147 genes com expressão diferenciada entre os casos de câncer de próstata, seis genes (PSMA, TMEFF2, GREB1, TH1L, IgH3 e PGC) foram selecionados. Estes genes foram então testados quanto a seu valor diagnóstico no câncer da próstata através da técnica de reação em cadeia da polimerase quantitativa com transcriptase reversa. Na primeira etapa do estudo, amostras de tecido maligno de 33 pacientes com câncer de próstata foram avaliadas. O grupo controle foi composto de nove pacientes com hiperplasia benigna da próstata. $\mathrm{Na}$ segunda etapa do estudo foram analisadas amostras de tecido benigno dos demais 17 pacientes com câncer da próstata. O mesmo grupo controle foi utilizado para comparação. RESULTADOS: A análise demonstrou que o PSMA estava super-expresso (em média nove vezes) e o PGC sub-expresso (em média de $1,3 \times 10^{-4}$ vezes) no tecido neoplásico de todos os casos de câncer quando comparados com os casos de hiperplasia benigna. Os demais genes demonstraram um padrão de expressão variado, não permitindo a diferenciação entre os tecidos malignos e benignos. Quando estes resultados foram testados no tecido prostático benigno dos pacientes com câncer, o PGC manteve o mesmo padrão de expressão em todos os casos e o PSMA, apresentou-se super-expresso em $88 \%$ dos pacientes (média de 12 vezes), em relação aos casos de hiperplasia benigna. CONCLUSÃO: A combinação da super-expressão do $P S M A$ e sub-expressão do $P G C$ no tecido prostático pode representar uma evidência objetiva de presença de Cap. Análises clínicas prospectivas adicionais são necessárias para confirmar estes resultados. 
Descritores: 1.Próstata 2.Neoplasias prostáticas/diagnóstico 3.Biópsia; 4.Expressão gênica 


\section{SUMMARY}

Antunes AA. The role of Prostate Specific Membrane Antigen (PSMA) and Pepsinogen C (PGC) gene tissue expression as an adjunctive method to prostate cancer diagnosis [thesis]. São Paulo: Faculdade de Medicina, Universidade de São Paulo; 2008.

Introduction and objective: Prostate cancer $(\mathrm{PCa})$ diagnosis in men with persistently increased PSA after a negative initial prostate biopsy has become a great challenge for urologists and pathologists. Despite the use of several methods to increase the sensitivity of prostate biopsy, the false-negative rates remain substantial, leading many patients to undergo repeated procedures. We analyzed the diagnostic value of six genes in the prostatic tissue of patients with clinically localized PCa, in order to predict the presence of cancer. Methods: The study was comprised by 50 patients with clinically localized PCa who underwent radical prostatectomy. Gene selection was based on a microarray analysis of patients with PCa. Among the 4,147 genes with different expressions between two groups, six genes (PSMA, TMEFF2, GREB1, TH1L, $I g H 3$ and $P G C$ ) were selected. These genes were tested for its cancer diagnostic role using the quantitative reverse transcriptase polymerase chain reaction (qRT-PCR) method. In the first part of the study, malignant tissue samples from 33 patients were analyzed, and in the second part we analyzed benign tissue samples of the other 17 patients with $\mathrm{PCa}$. The control group was comprised of prostatic tissue samples of patients with benign prostatic hyperplasia (BPH). Results: The analysis of malignant prostatic tissue by qRTPCR showed that PSMA was over-expressed (mean nine times) and PGC was under-expressed (mean $1.3 \times 10^{-4}$ times) in all cases when compared to $\mathrm{BPH}$. The other four tested genes showed a variable expression pattern not allowing a differentiation between benign and malignant cases. When we tested these results in the benign prostate tissues from patients with $\mathrm{PCa}, P G C$ maintained the expression pattern, and PSMA, despite over-expression in most cases (mean 12 times), two cases (12\%) presented under-expression. Conclusions: $P G C$ under-expression and PSMA over-expression in the tissue may represent an objective evidence of prostate cancer and constitute a powerful adjunctive method in patients with negative prostate biopsy. Further prospective clinical analyses are necessary to confirm theses results.

Descriptors: 1.Prostate 2.Prostate neoplasms/diagnosis 3.Biopsy 4.Gene expression 
Introdução 


\section{INTRODUÇÃO}

O câncer da próstata (Cap) continua sendo a neoplasia não cutânea mais freqüente do homem, correspondendo a mais de $15 \%$ de todos os tipos de tumores, e à segunda causa de óbito por câncer, perdendo apenas para os tumores de pulmão. Em 2008, são esperados cerca de 186.320 novos casos diagnosticados e 28.660 óbitos pela doença nos Estados Unidos (Jemal et al., 2008). Estimativas brasileiras esperam que aproximadamente 49.530 novos casos sejam diagnosticados em 2008 , correspondendo a $28 \%$ de todos os tumores malignos não cutâneos do homem no Brasil (Brasil, 2008).

A descoberta do Antígeno Prostático Específico (PSA) em 1979 por Wang et al. (Wang et al., 1979) marcou o início de uma nova era no diagnóstico e tratamento dos pacientes com Cap. Os programas de detecção do Cap utilizando o PSA, levaram a um aumento significativo das taxas de diagnóstico desta patologia, entretanto sua baixa sensibilidade e especificidade tem sido um importante fator limitante do método (Catalona et al.,1994). Apesar de amplamente aceito como marcador do Cap, o PSA é específico do tecido prostático e não do Cap. Deste modo, seus níveis séricos também podem elevar-se em pacientes com hiperplasia benigna da próstata (HPB) ou prostatites (Schalken et al., 2005). Devido a sua baixa especificidade, quando uma biópsia prostática é realizada em pacientes com níveis de PSA entre 3,0 e $10,0 \mathrm{ng} / \mathrm{ml}$ são observadas taxas de resultados negativos de aproximadamente 70 a 80\% (Djavan et al., 2000). 
Ademais, níveis mais baixos de PSA não excluem a presença de Cap. No estudo de Thompson et al. (2004), que avaliou 2950 homens com níveis de PSA abaixo de $4,0 \mathrm{ng} / \mathrm{ml}$ e sem alteração no toque retal, que foram submetidos a biópsia prostática, foi demonstrado que $15 \%$ dos homens tinham Cap e destes 15\% já apresentavam escore de Gleason de 7 ou maior.

Com o intuito de melhorar a sensibilidade e a especificidade do método, várias formas de utilização do PSA foram propostas, incluindo a estratificação do PSA pelas faixas etárias (Oesterling et al., 1993), a razão do PSA pelo volume da próstata (densidade do PSA) (Benson et al., 1992), a variação do PSA no tempo (velocidade do PSA) (Carter et al., 1992), a razão do PSA livre pelo PSA total (\%PSAL/PSAT) (Partin et al., 1996), e o tempo de duplicação do PSA (Schmid et al., 1995). Como os níveis de PSA tendem a aumentar com a idade, Oesterling et al. (1993) determinaram valores de referência de acordo com as faixas etárias. Eles estudaram prospectivamente 471 homens saudáveis, com idades entre 40 e 79 anos participantes de um estudo para avaliar a história natural da HPB. Desta forma, indivíduos com 40 a 49 anos, 50 a 59 anos, 60 a 69 anos e 70 a 79 anos deveriam apresentar valores de PSA até $2,5 \mathrm{ng} / \mathrm{ml}, 3,5 \mathrm{ng} / \mathrm{ml}, 4,5 \mathrm{ng} / \mathrm{ml}$ e $6,5 \mathrm{ng} / \mathrm{ml}$ respectivamente. Baseado no fato de que os valores de PSA poderem ser influenciados pelo volume da próstata, Benson et al. (1992) descreveram o conceito de densidade do PSA (DPSA) e avaliaram seu valor preditivo no diagnóstico do Cap. Através da análise de 61 pacientes $(41 \mathrm{com}$ Cap e 20 com HPB), demonstraram que a DPSA média foi de 0,581 e 0,044 
para os pacientes com Cap e HPB respectivamente. Ademais, nenhum paciente com HPB apresentou DPSA maior que 0,117. Carter et al. (1992) avaliaram prospectivamente a variação do PSA no tempo em pacientes com diagnóstico de Cap e HPB e determinaram que nos pacientes com Cap, a velocidade do PSA geralmente é maior que $0,75 \mathrm{ng} / \mathrm{ml} / \mathrm{ano}$. Partin et al. (1996) avaliaram o valor diagnóstico da \%PSAL/PSAT em 217 pacientes com diagnóstico confirmado por biópsia (139 com Cap e 78 com HPB). Demonstraram uma relação significativa entre esta medida e a probabilidade de biópsia positiva, sendo que enquanto os pacientes com a relação menor ou igual a $10 \%$ apresentaram uma probabilidade de Cap de $63 \%$, os pacientes com uma relação maior ou igual a $26 \%$ apresentaram uma probabilidade de apenas 2\%. Finalmente, Schmid et al. (1995) acompanhando a velocidade de duplicação do PSA em 43 pacientes com Cap que não receberam tratamento, determinou que para tumores localizados o tempo médio de duplicação é de quatro anos e que os pacientes com HPB aumentam o PSA 12 vezes menos que os pacientes com Cap. No entanto, além de mais trabalhosas e algumas vezes não disponíveis, nenhuma destas formas de avaliação do PSA demonstrou ser superior a medida do seu valor absoluto no diagnóstico do Cap.

Apesar de toda atenção voltada para o PSA como teste de detecção do Cap, o método padrão ouro para o diagnóstico da doença é a biópsia transretal da próstata guiada por ultra-som (BTRUS). Entretanto, devido à baixa sensibilidade do ultra-som, os protocolos convencionais de biópsia têm demonstrado taxas elevadas de resultados falso-negativos. Recentemente, 
uma análise de 10429 BTRUS realizadas entre 1993 e 2001 e resgatadas de dois grandes bancos de dados norte-americanos demonstrou que o risco cumulativo de Cap aumenta significativamente com as biópsias repetidas. Desta forma, as taxas de detecção de Cap foram de $34 \%, 50 \%, 62 \%$ e $68 \%$ para os pacientes submetidos a uma, duas, três e quatro biópsias respectivamente (Welsh et al., 2007).

Durante a última década, vários métodos têm sido utilizados para melhorar a sensibilidade do ultra-som. Hass et al (Hass et al., 2007), investigaram o valor das biópsias extendidas (com maior número de fragmentos) para o diagnóstico do Cap em próstatas removidas de autópsias. Eles compararam biopsias com seis, 12 e 18 fragmentos, e definiram que as taxas de sensibilidade foram de $30 \%$, $53 \%$ e $53 \%$ respectivamente. A acurácia do ultra-som trans-retal com Doppler utilizando contraste foi testada em 230 homens submetidos a um programa de detecção de Cap. O câncer foi detectado em $30 \%$ dos homens e taxas similares foram observadas entre os pacientes submetidos à biópsia com e sem contraste (Frauscher et al., 2002). Finalmente, o valor da ressonância magnética com espectroscopia para o diagnóstico do Cap foi analisado prospectivamente em 24 pacientes consecutivos com uma ou mais biópsia prévia negativa realizada por PSA persistentemente elevado e/ou alteração no exame digital da próstata. O Cap foi diagnosticado em $29,2 \%$ dos casos e a sensibilidade, especificidade e acurácia do método foram de $71 \%, 82,4 \%$ e $75 \%$ respectivamente (Yuen et al., 2004). 
Com o intuito de melhorar as taxas de diagnóstico do Cap, vários marcadores biológicos têm sido isolados e testados no tecido prostático (Parekh et al., 2007). O PSCA (Prostate stem cell antigen) é uma glicoproteína específica expressada na superfície celular. A detecção do PSCA é possível no Cap e no sangue, e alguns autores tem demonstrado uma relação entre a expressão do PSCA e o risco de Cap (Hara et al., 2002). Estudos adicionais são necessários para confirmar seu papel na detecção do Cap. A AMACR (Alpha-methyl coenzyme-A racemase) também parece desempenhar algum papel na avaliação das biópsias prostáticas de difícil interpretação. Análises da expressão da $A M A C R$ por microarranjos de tecido em espécimes de próstata benigna, próstata atrófica, neoplasia intraepitelial prostática, Cap localizado e Cap metastático revelaram uma intensidade de marcação de 1,$31 ; 2,33 ; 2,67 ; 3,20$ e 2,50 respectivamente (Rubin et al., 2002). A perda da expressão da GSTP1 (Glutathione-Stransferase P1) devido a hipermetilação é outra alteração genômica encontrada freqüentemente nos casos de Cap. Harden et al (Harden et al., 2003) demonstraram que a combinação da histologia com o teste de metilação específica da GSTP1 por reação em cadeia da polimerase quantitativa detectou Cap com uma sensibilidade de $79 \%$, que representou uma melhora de $15 \%$ em comparação com a histologia isoladamente. Outros genes como o DD3 (PCA3) nos espécimes de biópsia prostáticos e fluidos corporais, e a Hepsina no tecido prostático também tem sido testados para o diagnóstico do Cap (de Kok et al, 2002; Magee et al, 2001), porém assim 
como os demais, sua utilidade clínica ainda é limitada até o presente momento.

Neste contexto, a análise de novos genes candidatos a marcadores de diagnóstico no Cap tem se tornado um grande desafio para urologistas, patologistas e biólogos. Um estudo prévio realizado em nosso laboratório utilizando a tecnologia do microarray (Agilent Technologies 44k whole human genome, duas cores) em pacientes com Cap resultou na identificação de 4147 genes com expressão diferenciada entre pacientes com características clínicas distintas (dados não publicados). Entre estes genes, o PSMA, uma glicoproteína transmenbrana tipo 2 altamente expressa no Cap (Ghosh e Heston, 2004), o TMEFF2, descrito como gene regulado pelos andrógenos com capacidade de inibir o crescimento das células do Cap (Gery et al., 2002), o GREB1, gene regulado por andrógenos e estrógenos com papel importante em tecidos responsivos à hormônios (Rae et al., 2006), o TH1, gene com ação reguladora do ciclo celular e distribuição preferencial nos tecidos urogenitais (Liu et al., 2004), o IGH3, presente na urina de pacientes com câncer avançado (Abdul e Hoosein, 1995) e o PGC, cuja expressão na próstata está intimamente ligada à expressão de receptores androgênicos (Konishi et al.,1999), foram selecionados. Até o presente momento nenhum destes genes tem sido utilizado como marcador de diagnóstico no Cap. A sua super-expressão ou sub-expressão na próstata serviria para reforçar ou descartar o diagnóstico de Cap e auxiliaria de forma importante as ações médicas nesses pacientes. 
Objetivo 


\section{OBJETIVO}

Avaliar o papel diagnóstico da expressão dos genes TH1, GREB1, PSMA, TMEFF2, PGC e IgH3 no tecido prostático de pacientes com Cap em comparação com o tecido prostático de pacientes com diagnóstico de hiperplasia benigna da próstata (HPB). 


\section{Material e Métodos}




\section{MATERIAL E MÉTODOS}

\subsection{Pacientes e amostras tumorais}

O estudo consistiu na análise de 50 pacientes com diagnóstico de Cap clinicamente localizado submetidos à prostatectomia radical entre setembro de 1997 e fevereiro de 2000. Os genes descritos foram avaliados quanto a seu valor diagnóstico através da técnica de reação em cadeia da polimerase quantitativa em tempo real (qRT-PCR). A tabela 1 descreve os genes estudados e a B2M que foi utilizada como controle endógeno (Patel et al, 2004)

Tabela 1. Identificadores dos genes analizados através da técnica de qRTPCR

\begin{tabular}{lll}
\hline \multicolumn{1}{c}{ Gene symbol } & \multicolumn{1}{c}{ Gene name } & \multicolumn{1}{c}{ Assays IDs } \\
\hline PGC & $\begin{array}{l}\text { progastricsin (pepsinogen C) } \\
\text { immunoglobulin heavy chain, gamma }\end{array}$ & Hs00160052_m1 \\
IGH3 & $\begin{array}{l}\text { Holypeptide } \\
\text { trihydrophobin Human 1 }\end{array}$ & Hs00212624_m1 \\
TH1 & $\begin{array}{l}\text { gene regulated by estrogen in breast } \\
\text { cancer }\end{array}$ & Hs00536409_m1 \\
GREB1 & transmembrane protein with EGF-like and & Hs00249367_m1 \\
TMEFF2 & two follistatin-like domains 2 & \\
& prostate- specific membrane antigen & Hs00379515_m1 \\
PSMA & beta-2-microglobulin & Hs00984230_m1 \\
B2M & &
\end{tabular}


$\mathrm{Na}$ primeira etapa do estudo foram analisadas amostras de tecido maligno de 33 pacientes com Cap (figura 1). A tabela 2 descreve as características demográficas dos 33 pacientes com diagnóstico de Cap de onde se pode observar que a idade mediana foi de 65 anos $(49-76)$ e o PSA mediano foi de $7,9 \mathrm{ng} / \mathrm{ml}(2,5-37,0)$. Escore de Gleason maior ou igual a 7 foi encontrado em $60,8 \%$ dos pacientes e $27,3 \%$ deles apresentaram doença extra-prostática.

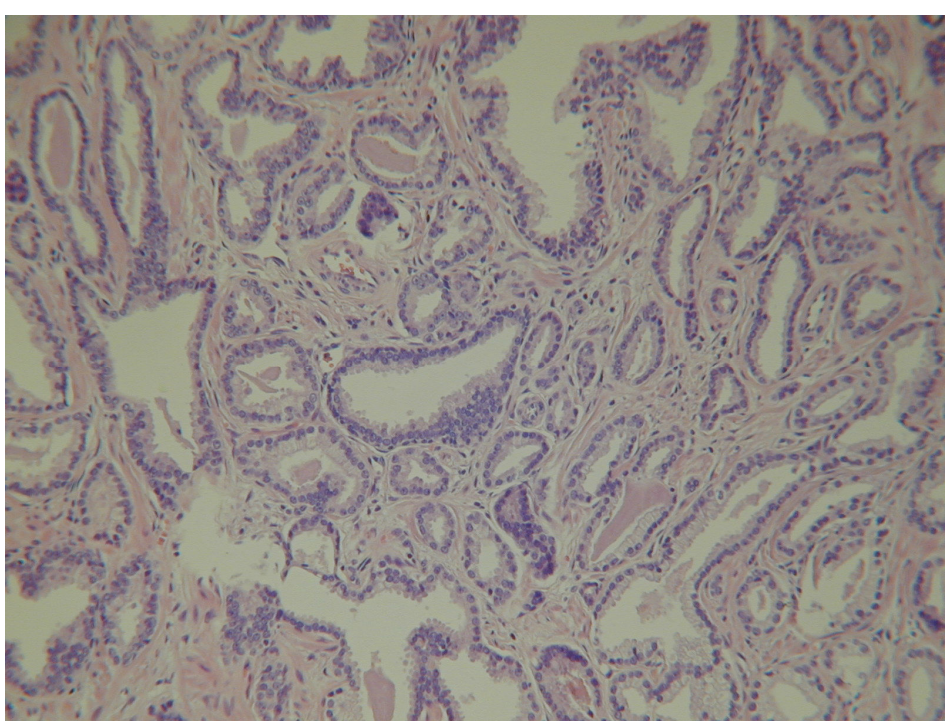

Figura 1. Tecido maligno de paciente com Cap $\left(\mathrm{H}_{\&} \mathrm{E} 100 \mathrm{X}\right)$. 
Tabela 2. Características dos 33 pacientes com Cap

\begin{tabular}{|c|c|}
\hline Número de pacientes & $\mathrm{n}=33$ \\
\hline \multicolumn{2}{|l|}{ Idade (anos) } \\
\hline Mediana (Q1 - Q3) & $65(60-70)$ \\
\hline Mínimo - Máximo & $49-76$ \\
\hline \multicolumn{2}{|l|}{ PSA (ng/mL) } \\
\hline Mediana (Q1 - Q3) & $7,9(6,0-12,0)$ \\
\hline Mínimo - Máximo & $2,5-37,0$ \\
\hline \multicolumn{2}{|l|}{ Estádio clínico } \\
\hline $\mathrm{T} 1$ & $14(42,4 \%)$ \\
\hline $\mathrm{T} 2$ & $19(57,6 \%)$ \\
\hline \multicolumn{2}{|l|}{ Escore de Gleason } \\
\hline Mediana (Q1 - Q3) & $7(5,0-8,0)$ \\
\hline Mínimo - Máximo & $4-9$ \\
\hline \multicolumn{2}{|l|}{ \%Tumor } \\
\hline Mediana (Q1 - Q3) & $12 \%(6,5 \%-20,0 \%)$ \\
\hline Mínimo - Máximo & $2 \%-38 \%$ \\
\hline Envolvimento da cápsula & $17(51,5 \%)$ \\
\hline Envolvimento das vesículas seminais & 0 \\
\hline Envolvimento dos linfonodos & 0 \\
\hline Envolvimento extra-prostático & $9(27,3 \%)$ \\
\hline \multicolumn{2}{|l|}{ Estádio patológico } \\
\hline $\mathrm{T} 2 \mathrm{~A}$ & $10(30,3 \%)$ \\
\hline $\mathrm{T} 2 \mathrm{~B}$ & $6(18,2 \%)$ \\
\hline $\mathrm{T} 2 \mathrm{C}$ & $8(24,2 \%)$ \\
\hline T3A & $9(27,2 \%)$ \\
\hline
\end{tabular}


O grupo controle consistiu de nove pacientes com diagnóstico clínico de HPB e indicação de tratamento cirúrgico (figura 2). Sintomas do trato urinário inferior de intensidade moderada a grave que não haviam respondido ao tratamento com medicações foram observados em $66,7 \%$ dos casos, e 33,3\% apresentavam-se em retenção urinária. A idade mediana foi de 73 anos, e o peso prostático mediano pelo USG foi de $112 \mathrm{~g}$ com variação de 80 a $176 \mathrm{~g}$. O PSA mediano foi de $10,0 \mathrm{ng} / \mathrm{ml}$, e pelo menos uma BTRUS pré-operatória foi realizada em $66,7 \%$ dos pacientes. Oito pacientes foram submetidos à prostatectomia retropúbica pela técnica de Millin modificada por Srougi (Srougi et al., 2003), e um à ressecção transuretral da próstata. Todos os pacientes apresentaram resultado patológico negativo para Cap. A tabela 3 descreve as características dos nove pacientes com diagnóstico de HPB.

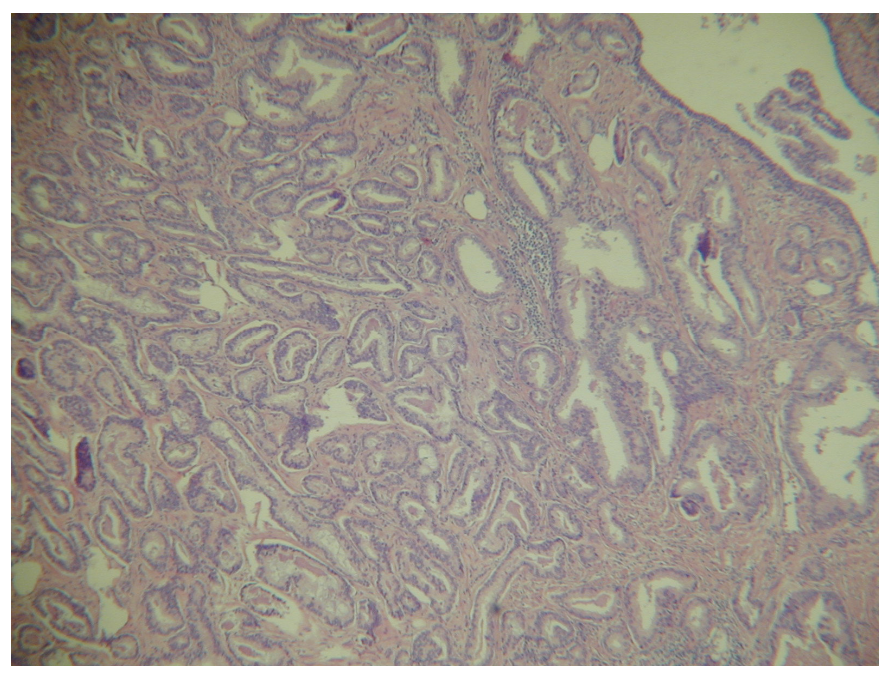

Figura 2. Tecido prostático de paciente com HPB ( $\left.\mathrm{H}_{\&} \mathrm{E} 40 \mathrm{X}\right)$. 
Tabela 3. Características dos nove pacientes com HPB

\begin{tabular}{|c|c|}
\hline Número de pacientes & $n=9$ \\
\hline \multicolumn{2}{|l|}{ Idade (anos) } \\
\hline Mediana (Q1 - Q3) & $73(69,5-77,3)$ \\
\hline Mínimo - Máximo & $66-86$ \\
\hline \multicolumn{2}{|l|}{ PSA (ng/mL) } \\
\hline Mediana (Q1 - Q3) & $10(9,02-11,58)$ \\
\hline Mínimo - Máximo & $4,0-15,0$ \\
\hline \multicolumn{2}{|l|}{ Volume prostático pelo toque retal (g) } \\
\hline Mediana (Q1 - Q3) & $100(85-120)$ \\
\hline Mínimo - Máximo & $70-120$ \\
\hline \multicolumn{2}{|l|}{ Volme prostático pelo USG (g) } \\
\hline Mediana (Q1 - Q3) & $112(98,0-131,5)$ \\
\hline Mínimo - Máximo & $80-176$ \\
\hline \multicolumn{2}{|l|}{ Peso da peça cirúrgica $(\mathrm{g})$} \\
\hline Mediana (Q1 - Q3) & $67(47,7-106,7)$ \\
\hline Mínimo - Máximo & $15,0-120,3$ \\
\hline \multicolumn{2}{|l|}{ Número de biópsias pré-operatórias } \\
\hline 0 & $3(33,3 \%)$ \\
\hline 1 & $2(22,2 \%)$ \\
\hline 3 & $3(33,3 \%)$ \\
\hline 4 & $1(11,2 \%)$ \\
\hline \multicolumn{2}{|l|}{ Presença de retenção urinária } \\
\hline Sim & $3(33,3 \%)$ \\
\hline Não & $6(66,7 \%)$ \\
\hline \multicolumn{2}{|l|}{ Tipo de cirurgia } \\
\hline Prostatectomia retropúbica (Millin) & $8(88,9 \%)$ \\
\hline RTUP & $1(11,1 \%)$ \\
\hline \multicolumn{2}{|l|}{ Anátomo patológico } \\
\hline HPB & $6(66,7 \%)$ \\
\hline HPB + prostatite crônica & $3(33,3 \%)$ \\
\hline
\end{tabular}


$\mathrm{Na}$ segunda etapa do estudo, amostras de tecido prostático normal dos 17 pacientes restantes com diagnóstico de Cap (figura 3) foram comparadas com amostras dos mesmos nove pacientes com diagnóstico de HPB. A tabela 4 descreve as características dos 17 pacientes com Cap utilizados na segunda etapa do estudo.

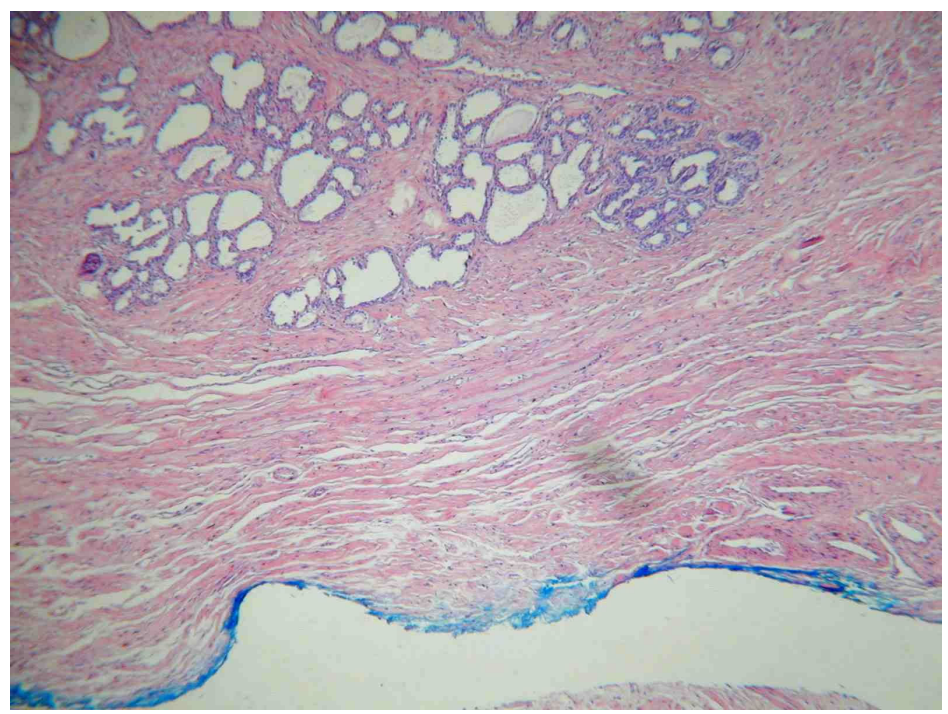

Figura 3. Tecido normal de paciente com Cap $\left(\mathrm{H}_{\&} \mathrm{E} 40 \mathrm{X}\right)$. 
Tabela 4. Características dos 17 pacientes com Cap cujo tecido benigno foi analisado

\begin{tabular}{|c|c|}
\hline Número de pacientes & $\mathrm{n}=17$ \\
\hline \multicolumn{2}{|l|}{ Idade (anos) } \\
\hline Mediana (Q1 - Q3) & $57(52-67)$ \\
\hline Mínimo - Máximo & $48-73$ \\
\hline \multicolumn{2}{|l|}{ PSA (ng/mL) } \\
\hline Mediana (Q1 - Q3) & $6,1(5,3-11,6)$ \\
\hline Mínimo - Máximo & $0,9-16,0$ \\
\hline \multicolumn{2}{|l|}{ Estádio clínico } \\
\hline $\mathrm{T} 1 \mathrm{C}$ & $11(64,7 \%)$ \\
\hline $\mathrm{T} 2 \mathrm{~A}$ & $4(23,5 \%)$ \\
\hline $\mathrm{T} 2 \mathrm{C}$ & $2(11,8 \%)$ \\
\hline \multicolumn{2}{|l|}{ Escore de Gleason } \\
\hline Mediana (Q1 - Q3) & $6(6-7)$ \\
\hline Mínimo - Máximo & $6-7$ \\
\hline Envolvimento da cápsula & $7(41,2 \%)$ \\
\hline Envolvimento das vesículas seminais & 0 \\
\hline Envolvimento dos linfonodos & 0 \\
\hline Envolvimento extra-prostático & $3(17,6 \%)$ \\
\hline \multicolumn{2}{|l|}{ Estádio patológico } \\
\hline $\mathrm{T} 2 \mathrm{~A}$ & $4(23,5 \%)$ \\
\hline $\mathrm{T} 2 \mathrm{~B}$ & $2(11,8 \%)$ \\
\hline $\mathrm{T} 2 \mathrm{C}$ & $8(47,1 \%)$ \\
\hline T3A & $3(17,6 \%)$ \\
\hline
\end{tabular}

Um termo de consentimento foi obtido de cada paciente e o estudo foi aprovado pela comissão de ética do Hospital das Clínicas da Faculdade de Medicina da Universidade de São Paulo. O trabalho foi financiado pela 
Fundação de Amparo à Pesquisa do Estado de São Paulo (Fapesp) sob o protocolo \#2006/56492-5.

\subsection{Exame Anátomo-patológico:}

\subsubsection{Exame Macroscópico}

Os espécimes cirúrgicos foram recebidos a fresco, sendo identificada à palpação área provável de tumor, sendo efetuado um corte de aproximadamente $1 \mathrm{~cm}^{2}, 3$ a $4 \mathrm{~mm}$ de espessura que foi armazenado a $80^{\circ} \mathrm{C}$. Após este procedimento a glândula foi fixada em formalina tamponada $10 \%$ por um período variável de quatro a 16 h. Toda a glândula foi submetida a estudo histológico seguindo recomendações previamente descritas (Bostwik e Foster, 1998). Após a pesagem e medição da glândula, foram realizados cortes transversais finos nas margens cirúrgicas referentes ao colo vesical e ápice da próstata. As vesículas seminais foram seccionadas na base e cortes longitudinais foram submetidos a exame histológico. Toda a glândula foi incluída para estudo após suas margens serem pintadas com tinta nanquim. Os lobos direito e esquerdo foram separados, sendo realizados cortes transversais seqüenciais a cada $3 \mathrm{~mm}$, designados da região proximal em direção a distal. De oito a 10 cortes de cada lobo foram incluídos para estudo histológico. Foram dissecados linfonodos da gordura referente à ressecção da cadeia obturatória e cortes representativos de cada estrutura nodular foram incluídos para estudo. 


\subsubsection{Exame Microscópico}

Os espécimes foram submetidos a processamento habitual com desidratação em álcool e clareamento em xilol, seguido por inclusão em parafina. Cortes de quatro a seis $\mu \mathrm{m}$ foram corados pela Hematoxilina e Eosina e analisados em microscópio óptico.

Foram analisados os seguintes parâmetros:

Grau Histológico - O grau histológico de Gleason foi utilizado para avaliação de diferenciação histológica. Foram considerados os dois padrões predominantes de Gleason, variáveis de 1 a 5 , que somados resultam no escore de Gleason, variável de 2 a 10 (Gleason,1992).

Volume Tumoral - A avaliação do volume tumoral foi realizada com o auxílio de cartão quadriculado, como descrito por Humphrey e Vollmer (1990), brevemente: Ao exame microscópico, as áreas da glândula infiltradas por tumor foram delineadas com uso de caneta de tinta indelével. As lâminas marcadas foram colocadas sobre cartão milimetrado e a porcentagem de quadrados ocupados por adenocarcinoma foi considerada em relação a toda a área ocupada pelo corte. Assim o volume tumoral corresponde à porcentagem de área da glândula ocupada por tumor.

Infiltração do Tecido Extra Prostático - A invasão do tecido adiposo e do plexo vásculo-nervoso periprostático foi considerado como envolvimento do tecido extraprostático e, portanto doença não órgão-confinada. 
Infiltração das Vesículas Seminais - Somente a infiltração do parênquima da vesícula seminal foi considerada, não sendo considerados os tumores invasivos na região adventicial.

Metástases Linfonodais - Linfonodos obturatórios com tumor foram considerados positivos, não havendo discriminação quanto à micro ou macrometástases.

Estadiamento - Foi utilizado sistema TNM 2002 de estadiamento (UICC, 2002).

\subsection{Processamento da amostra}

Dez cortes de $10 \mu \mathrm{m}$ serão feitos em criostato, com temperatura de $20^{\circ} \mathrm{C}$, e acondicionados em microtubos de $1,5 \mathrm{~mL}$, autoclavados, sendo tomados todos os cuidados para evitar a contaminação entre as amostras ou degradação do RNA. Um dos cortes é colocado em lâmina, fixado em formalina $10 \%$, corado pela hematoxilina e eosina e examinado ao microscópio para comprovação da existência de tumor com a porcentagem mínima de $75 \%$ nos casos de câncer, e ausência de tumor nos casos de HPB.

\subsection{Extração de RNA e síntese de cDNA}

Os espécimes congelados a $-80^{\circ} \mathrm{C}$ foram cortados em criostato a $30^{\circ} \mathrm{C}$, sendo retirados 10 cortes de $10 \mu \mathrm{m}$ e colocados em tubo de 
microcentrífuga de $1,5 \mathrm{~mL}$ estéril. Os cortes do tecido congelado foram macerados em nitrogênio liquído e o RNA total extraído das células com Trizol, seguindo protocolo do fabricante (Invitrogen Life Technologies).

O tecido congelado foi transferido para recipiente de porcelana contendo nitrogênio líquido e macerado com auxílio do pistilo. O tecido macerado foi transferido para um microtubo e a este adicionado $1 \mathrm{~mL}$ de Trizol. O conteúdo foi homogeneizado por inversão e incubado a temperatura ambiente por cinco minutos. Após este período $0,2 \mathrm{~mL}$ de clorofórmio foi acrescentado à amostra e esta imediatamente homogeneizada por agitação vigorosa. Seguindo-se três minutos de incubação a temperatura ambiente, o material foi submetido à centrifugação a $12.000 \mathrm{~g}$ por 15 minutos, a $4^{\circ} \mathrm{C}$. A fase aquosa superior foi então transferida para um novo tubo contendo um volume de álcool isopropílico. Após incubação a temperatura ambiente por 10 minutos, a amostra foi centrifugada $\left(12.000 \mathrm{~g}, 10\right.$ minutos, $\left.4^{\circ} \mathrm{C}\right)$ e o sobrenadante descartado. $\mathrm{O}$ precipitado foi lavado com $0,5 \mathrm{~mL}$ de etanol $75 \%$ (v/v) por centrifugação (7.500g, cinco minutos $4^{\circ} \mathrm{C}$ ). Por fim, o etanol foi desprezado e o precipitado seco por cinco minutos à temperatura ambiente antes de ser re-suspenso em $\mathrm{H}_{2} \mathrm{O}$ livre de RNase/DNase.

A pureza e concentração do RNA foram mensuradas em espectrofotômetro (260/280 nM). E a integridade verificada em Agilent 2100 Bioanalyzer (Agilent technologies, CA, USA). 
A síntese do cDNA foi realizada a partir de $5 \mu \mathrm{g}$ de RNA utilizando-se a enzima $M-M L V$ transcriptase reversa e iniciadores randômicos (Invitrogen Life Technologies).

O RNA total foi diluído em $\mathrm{H}_{2} \mathrm{O}$ livre de nucleases em um volume final de $11 \mu \mathrm{L}$. A este volume foram acrescentados $1 \mu \mathrm{L}$ de oligonucleotídeos randômicos $(3 \mu \mathrm{g} / \mu \mathrm{L})$ e $1 \mu \mathrm{L}$ do mix de dNTPs $(10 \mathrm{nM})$. A mistura foi submetida a aquecimento a $65^{\circ} \mathrm{C}$ por cinco minutos, e em seguida colocada em gelo antes da adição de $4 \mu \mathrm{L}$ do tampão da enzima (5X) e $3 \mu$ de DTT $(0,1 \mathrm{M})$. A reação foi então incubada a $37^{\circ} \mathrm{C}$ por três minutos, $1 \mu \mathrm{L}(200 \mathrm{U}) \mathrm{da}$ enzima M-MLV transcriptase reversa adicionado, permanecendo a reação a $37^{\circ} \mathrm{C}$ por uma hora. Após este período a enzima foi inativada a $95^{\circ} \mathrm{C}$ por cinco minutos. Ao volume final da reação de $20 \mu \mathrm{L}$ foram adicionados $80 \mu \mathrm{L}$ de água e o cDNA armazenado a $-20^{\circ} \mathrm{C}$ até o uso.

\section{5 qRT-PCR e expressão gênica}

A expressão dos genes estudados foi avaliada a partir do cDNA utilizando a metodologia de transcrição reversa seguida de reação em cadeia da polimerase quantitativa em tempo real (qRT-PCR) (plataforma Abi7500) utilizando-se o protocolo TaqMan ${ }^{\circledR}$ (Applied Biosystems). Este protocolo utiliza dois iniciadores não fluorescentes e uma sonda com dupla marcação que se anela à região localizada entre os iniciadores. Esta marcação dupla é formada por um fluoróforo que emite luz quando excitado e um quencher que absorve a luz emitida pelo fluoróforo. Durante os ciclos 
da PCR, a sonda é quebrada pela Taq polimerase na etapa de extensão do iniciador anelado. Esta quebra da sonda elimina a absorção pelo quencher da fluorescência emitida que pode ser então medida através de uma câmera situada na parte superior do equipamento. A quantificação da emissão absorvida pela câmera após quebra da sonda permite a quantificação indireta do DNA alvo contido na reação após cada ciclo da PCR.

Experimentos iniciais de quantificação absoluta com o gene controle 32-microglobulina (B2M) validaram o cDNA antes da realização dos experimentos de quantificação do gene de interesse. Para quantificação relativa dos genes em estudo normalizamos a expressão destes em relação à expressão do gene controle $B 2 M$.

Os experimentos de qRT-PCR foram realizados em soluções contendo

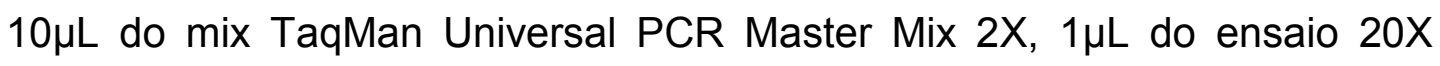
composto por iniciadores e sonda específicos, e $2 \mu \mathrm{L}$ de cDNA em um volume final de $20 \mu \mathrm{L}$. A condição usual de programação dos ciclos foi um passo a $50^{\circ} \mathrm{C}$ por dois minutos, um passo a $94^{\circ} \mathrm{C}$ por 10 minutos seguidos de 40 ciclos de $95^{\circ} \mathrm{C}$ por 30 segundos e $60^{\circ} \mathrm{C}$ por 60 segundos.

Para calcular a expressão relativa dos seis genes alvo foi utilizado o método $\Delta \Delta \mathrm{C}_{\mathrm{T}}$, que utiliza a seguinte fórmula: $\Delta \Delta \mathrm{C}_{\mathrm{T}}=\left(\mathrm{C}_{\mathrm{T}}\right.$ do gene alvo, amostra de Cap $-\mathrm{C}_{\mathrm{T}}$ do controle endógeno, amostra de $\left.\mathrm{Cap}\right)-\left(\mathrm{C}_{\mathrm{T}}\right.$ do gene alvo, amostra de HPB $-\mathrm{C}_{T}$ do controle endógeno, amostra de HPB). $\mathrm{O}$ número de vezes que ocorre a mudança da expressão gênica é calculado como $2^{-\Delta \Delta C T}$ (Livak et al., 2001). 


\subsection{Análise estatística}

As variáveis quantitativas foram resumidas através da mediana, variação inter-quartil (Q1-Q3) e valores de mínimo e máximo. Já as variáveis qualitativas foram expressas através do número e porcentagem.

A comparação dos níveis de expressão tecidual da B2M entre amostras de HPB, tecido normal de pacientes com câncer e tecido maligno de pacientes com câncer foi feita através do teste não paramétrico de KruskalWallis.

Para análise dos níveis de expressão do PGC e PSMA de acordo com o estádio patológico e do escore de Gleason, inicialmente foi construído um box-plot para avaliar descritivamente o comportamento dos genes de acordo com o estádio patológico e o escore de Gleason e para a comparação entre as categorias foi utilizado o teste de Mann-Whitney.

Para análise estatística foi utilizado o software SPSS 15.0. Em toda análise estatística foi adotado um nível de significância de $5 \%$, ou seja, foram considerados como estatisticamente significantes os resultados que apresentaram $p$-valor inferior a $5 \%(p<0,05)$. 
Resultados 


\section{RESULTADOS}

A comparação dos níveis de expressão tecidual da $B 2 M$ entre as amostras de HPB, tecido normal de pacientes com câncer e tecido maligno de pacientes com câncer não revelou diferença estatística (figura 1).

$\mathrm{Na}$ primeira etapa do estudo a análise dos seis genes através do método de qRT-PCR no tecido maligno demonstrou que o PSMA apresentou-se sempre super-expresso e o PGC sempre sub-expresso em todos os casos de Cap quando comparados com os casos de HPB (figura 2). A super-expressão do PSMA foi em média de nove vezes e a sub-expressão do PGC em média de $1,3 \times 10^{-4}$ vezes. Os quatro demais genes testados demonstraram um padrão de expressão variada não permitindo a diferenciação entre os casos malignos e benignos. A tabela 5 mostra a expressão mediana dos seis genes estudados.

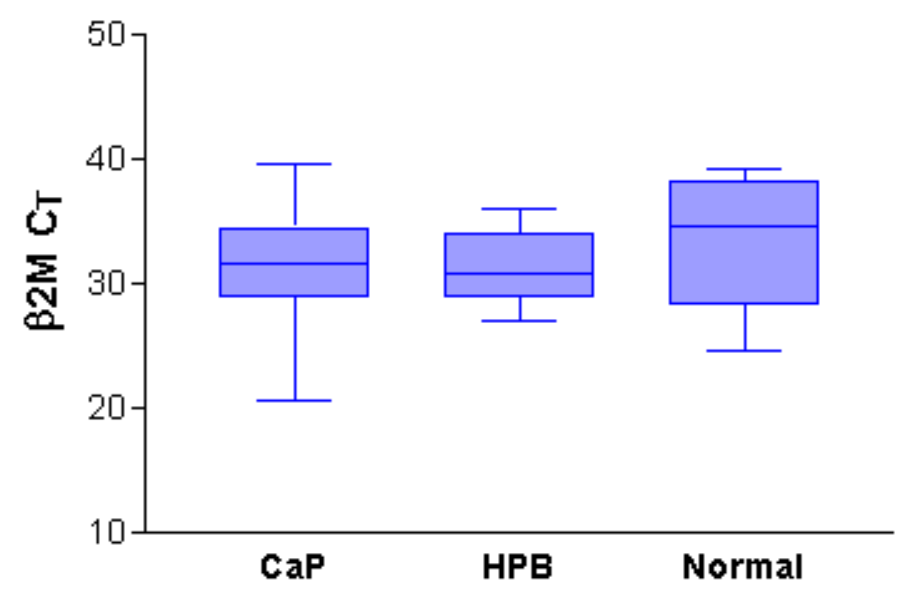

Figura 4. Expressão quantitativa da $B 2 M$ de acordo com os tecidos analisados $(p=0,325)$. 


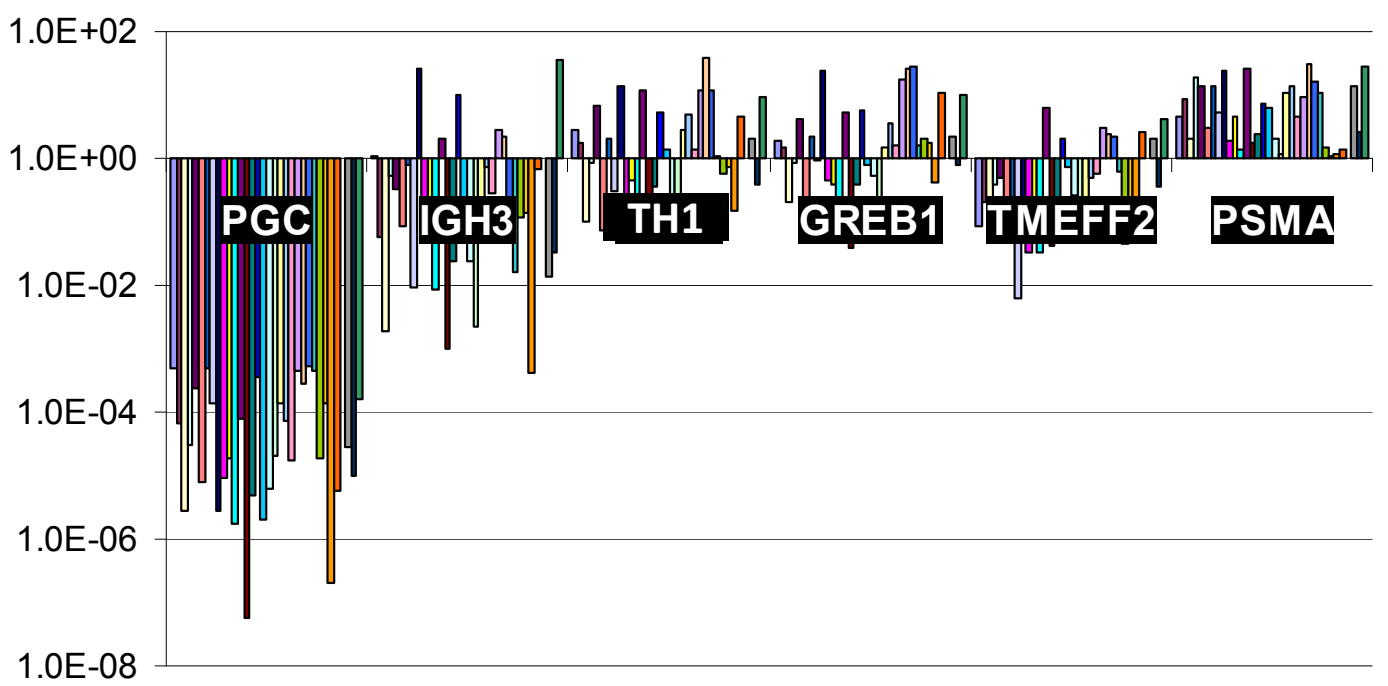

Figura 5. Expressão quantitativa dos genes PSMA, TMEFF2, GREB1, TH1, IGH3 e PGC no tecido do Cap em relação ao calibrador HPB. 
Tabela 5. Expressão mediana dos seis genes estudados através do qRTPCR nos 33 pacientes com Cap.

\begin{tabular}{lc}
\hline Número de pacientes & $\mathrm{n}=33$ \\
\hline PGC & $2,1.10^{-5}\left(5,3.10^{-6}-1,9.10^{-4}\right)$ \\
Mediana (Q1 - Q3) & $5,5.10^{-8}-5,3.10^{-4}$ \\
Mínimo - Máximo & \\
\hline IGH3 & $1,3.10^{-1}\left(2,0.10^{-2}-7,7.10^{-1}\right)$ \\
Mediana (Q1 - Q3) & $4,0.10^{-4}-2,6.10^{+1}$ \\
Mínimo - Máximo & $1,4.10^{0}\left(2,7.10^{-1}-5,2.10^{0}\right)$ \\
TH1 & $6,0.10^{-2}-3,8.10^{+1}$ \\
Mediana (Q1 - Q3) & $1,6.10^{0}\left(4,2.10^{-1}-4,9.10^{0}\right)$ \\
Mínimo - Máximo & $3,9.10^{-2}-2,8.10^{+1}$ \\
GREB1 & $1,1.10^{0}-3,0.10^{1}$ \\
Mediana (Q1 - Q3) & \\
Mínimo - Máximo & $2,1.10^{-1}\left(9,5.10^{-2}-1,3.10^{0}\right)$ \\
\hline TMEFF2 & $6,3.10^{-3}-6,3.10^{0}$ \\
Mediana (Q1 - Q3) & $5,1.10^{0}\left(1,9.10^{0}-1,3.10^{0}\right)$ \\
Mínimo - Máximo & \\
\hline PSMA & \\
Mediana (Q1 - Q3) & \\
Mínimo - Máximo & \\
\hline
\end{tabular}

A análise da expressão do $P G C$ e do PSMA de acordo com o estádio patológico está ilustrada nas figuras 3 e 4 . Enquanto que a expressão do PSMA não foi estatisticamente diferente entre os pacientes com estádio T2 e T3 ( $p=0,237)$, o PGC esteve mais sub-expresso nos pacientes com estádio T3 ( $\mathrm{p}=0,018)$. A análise da expressão do $P G C$ e do PSMA de acordo com o escore de Gleason está ilustrada nas figuras 5 e 6 . A expressão de ambos 
os genes foi estatisticamente semelhante entre os pacientes com escore de Gleason $<7$ ou $\geq 7$.

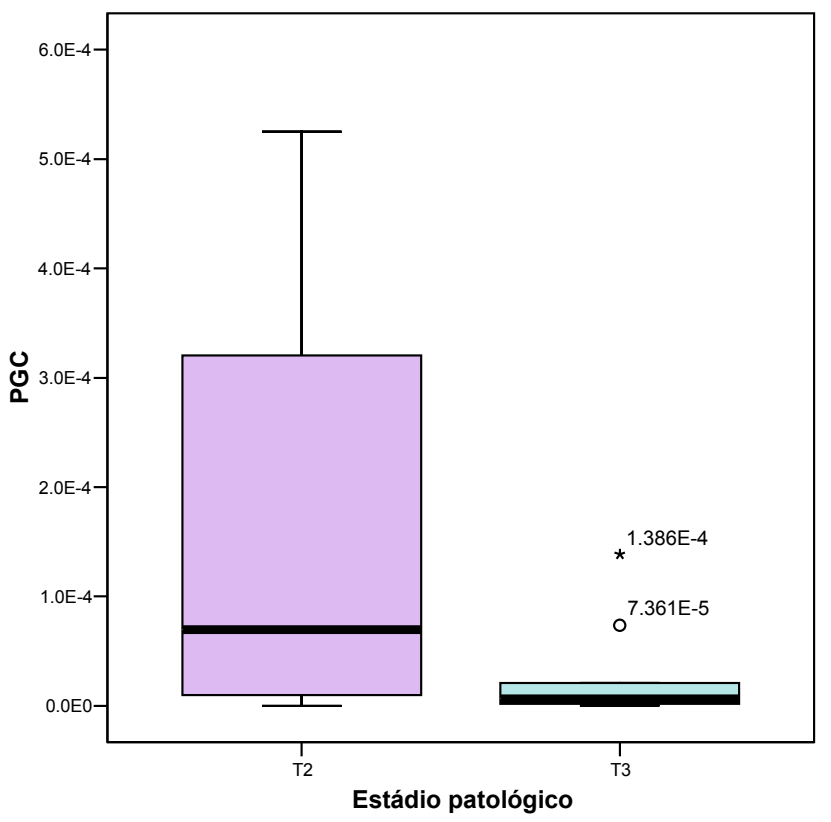

Figura 6. Box-plot da expressão mediana do $P G C$ de acordo com o estádio patológico T2 $\left(7,0 \cdot 10^{-5}\right.$ vezes $)$ e T3 $\left(6,5 \cdot 10^{-6}\right.$ vezes $)(p=0,018)$.

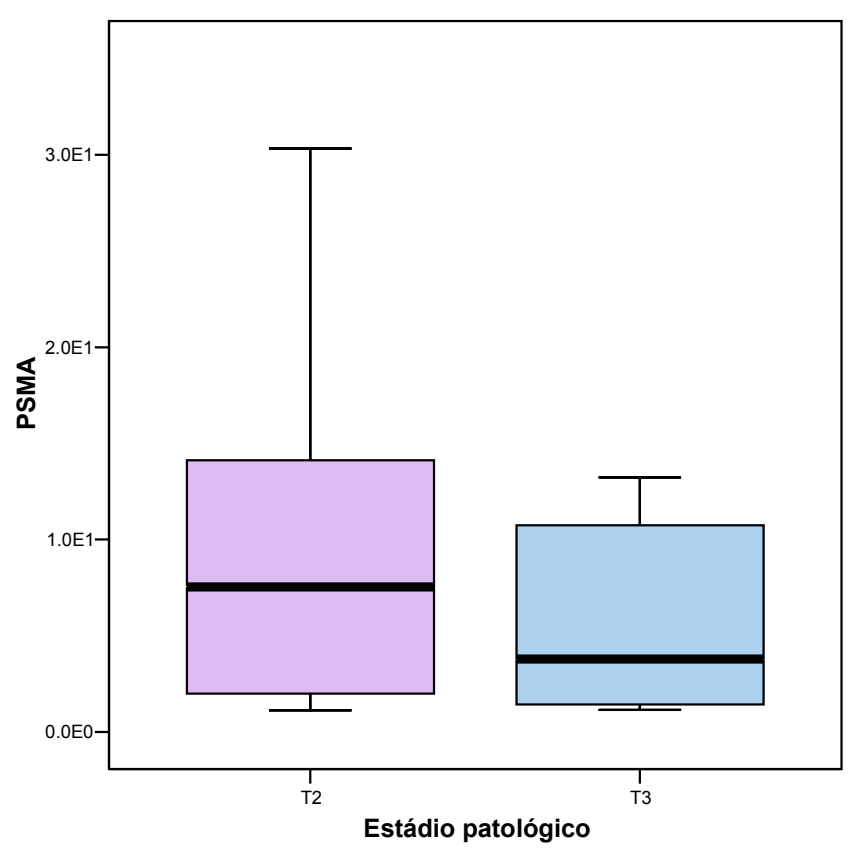

Figura 7. Box-plot da expressão mediana do PSMA de acordo com o estádio patológico T2 $\left(7,5 \cdot 10^{0}\right.$ vezes $)$ e T3 $\left(3,8 \cdot 10^{\circ}\right.$ vezes $)(p=0,237)$. 


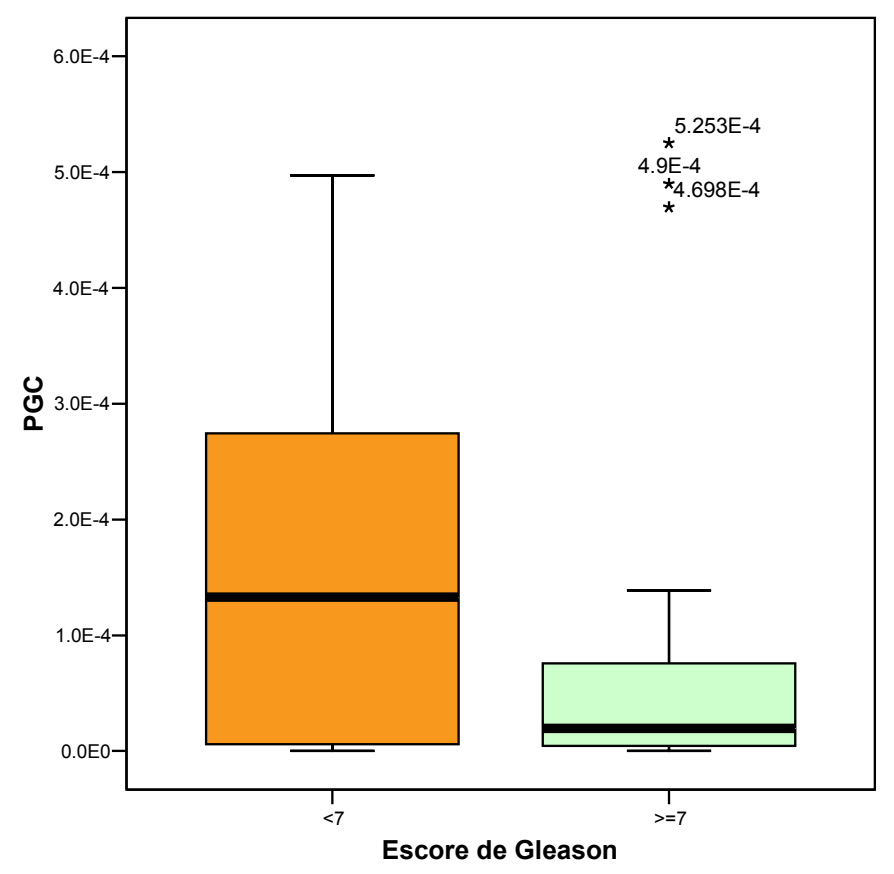

Figura 8. Box-plot da expressão mediana do $P G C$ de acordo com o escore de Gleason $<7\left(1,3 \cdot 10^{-4}\right.$ vezes $)$ e $\geq 7\left(2,0.10^{-5}\right.$ vezes $)(p=0,501)$.

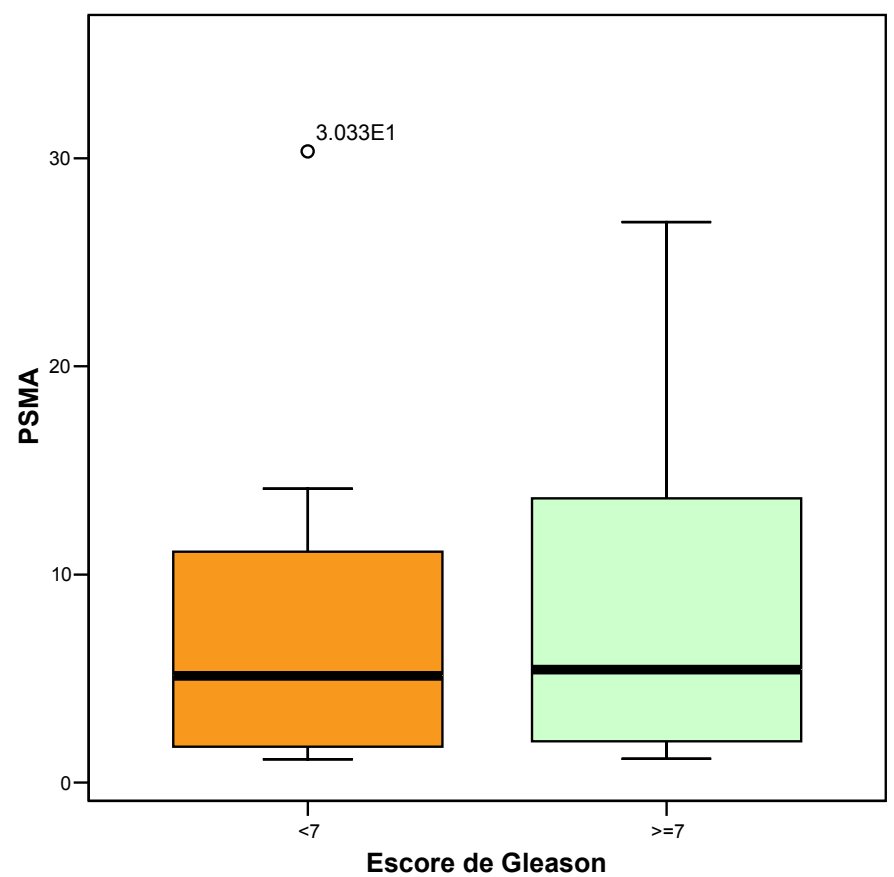

Figura 9. Box-plot da expressão mediana do PSMA de acordo com o escore de Gleason $<7\left(5,1 \cdot 10^{0}\right.$ vezes $)$ e $\geq 7\left(5,4.10^{\circ}\right.$ vezes $)(p=0,703)$ 
Com o objetivo de avaliar se este padrão de expressão seria constante no tecido prostático benigno de pacientes com Cap, comparamos o padrão de expressão do PSMA e do $P G C$ dos 17 pacientes restantes com Cap com o de nove pacientes com diagnóstico de HPB. Como demonstrado na figura 7, da mesma forma que no tecido maligno, o PGC manteve-se sub-expresso no tecido benigno de todos os casos de Cap (em média 1,3 $\times 10^{-4}$ vezes). Em relação ao PSMA, apesar de super-expresso na maioria dos casos (média de 12 vezes), dois pacientes (12\%) apresentaram sub-expressão em relação à HPB. Estes pacientes apresentavam PSA pré-operatório de 5,3 e 6,8 ng/ml, ambos apresentaram tumores com escore de Gleason 6 e estádio patológico T2A e T2B respectivamente.

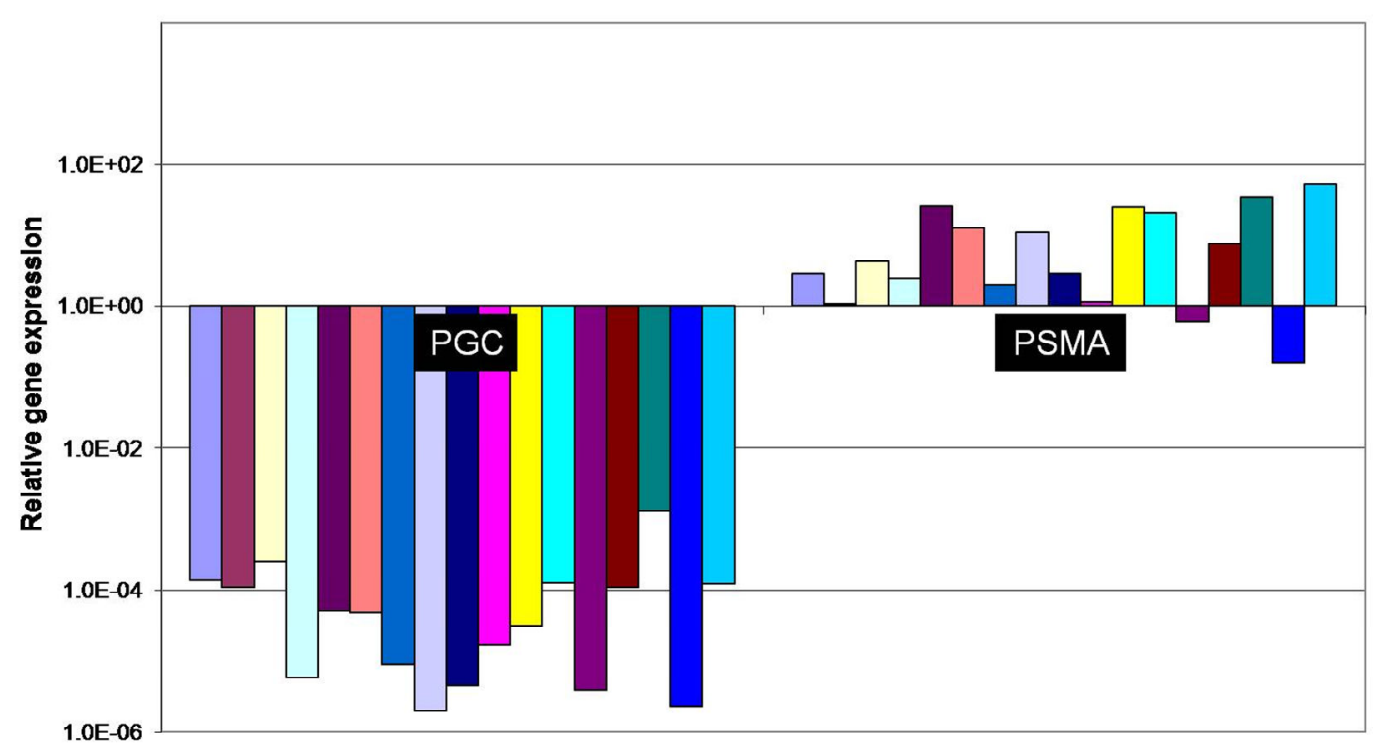

Figura 10. Padrão de expressão do $P G C$ e $P S M A$ no tecido benigno de pacientes com Cap. A expressão quantitativa dos genes PGC e PSMA é relativa ao calibrador HPB. O nível de expressão foi calculado utilizando o método $\Delta \Delta C \mathrm{~T}\left(Q_{R e l}=2^{-\Delta \Delta C T}\right)$. 
Discussão 


\section{DISCUSSÃO}

A presente análise demonstrou que a expressão tecidual do $P G C$ discriminou o tecido prostático de pacientes com Cap dos pacientes com HPB. Ademais, o fato deste padrão de expressão ter se mantido em outros locais da glândula além da área tumoral representa outro achado importante desde que pode contornar o problema da falta de sensibilidade do ultra-som observada comumente nas biópsias prostáticas. Apesar de o PSMA estar sempre super-expresso no tecido maligno em ralação à HPB, dois $(12 \%)$ casos apresentaram sub-expressão no tecido benigno de pacientes com CaP.

Devido a seu papel na degradação da matriz extracelular, facilitando a invasão tumoral e a metástase, as enzimas proteolíticas são relacionadas a diversos processos tumorais (Diamandis et al., 1997). O pepsinogênio C $(P G C)$ é uma aspartil protease sintetizada principalmente na mucosa gástrica, que desempenha um papel importante na digestão de proteínas. Quando secretada no lúmem do estômago sofre ativação no pH ácido e é transformada em pepsina C (Sánchez et al., 1992). O gene do PGC é localizado no cromossomo 6, entre as regiões 6 p11 e 6p21.3. Estudos recentes têm apontado para um polimorfismo de inserção/deleção de aproximadamente $100 \mathrm{pb}$, localizado entre os exons 7 e 8 como um marcador de suscetibilidade para o desenvolvimento do adenocarcinoma gástrico (Liu et al., 2003). 
Entretanto, de forma surpreendente, estudos recentes tem relatado a expressão ectópica do $P G C$ em carcinomas de origem extra-gástrica, como carcinoma cervical, endometrial, ovariano, pancreático e de mama, assim como em melanomas (Díaz et al, 2002). Ademais, tem sido demonstrado que a expressão do $P G C$ pelo carcinoma da mama está significativamente associada com parâmetros clínico-patológicos do tumor relacionados a um bom prognóstico, como grau bem diferenciado e status positivo dos receptores estrogênicos, assim como com uma maior sobrevida global dos pacientes (Vizoso et al., 1995; Serra et al., 1999). Uma possível explicação para o fato da expressão do $P G C$ pelas células do carcinoma de mama oferecer uma vantagem prognóstica é que a sua presença deve refletir a existência de uma via de receptor hormonal completa. Em concordância com esta hipótese, Balbín e López-Otín (1996), demonstraram que os androgênios, os glicocorticóides e as progestinas super-regulam a expressão do $P G C$ nas células do carcinoma de mama humano. Apesar destes achados, a importância exata do $P G C$ nos tumores de origem extragástrica ainda é desconhecida.

Em condições normais, o PGC também pode ser encontrado na zona central da próstata, mas não na zona periférica, onde surge a maioria dos Cap (Reese et al., 1986). Este padrão de expressão é modificado em glândulas anormais, com a expressão do $P G C$ sendo observada nos tumores da zona periférica. Análises de imuno-histoquímica demonstraram que a expressão do $P G C$ está intimamente ligada à expressão de receptores androgênicos em espécimes de próstata de pacientes com Cap. No estudo 
de Konishi et al (1999), 60\% dos tumores obtidos de espécimes de prostatectomia radical foram positivos para o $P G C$, e os receptores androgênicos foram detectados em $87 \%$ destas lesões. Por outro lado, apenas $53 \%$ dos tumores $P G C$-negativos expressaram receptores androgênicos. Por este motivo, Díaz et al (2002), testaram o significado clínico do PGC em amostras tumorais de pacientes com Cap estádio D2 que receberam terapia anti-androgênica. Entre os 28 pacientes analisados, $43 \%$ demonstraram forte imunomarcação positiva para o PGC. Durante o período de seguimento, ocorreram oito óbitos por progressão tumoral entre os 16 pacientes com tumores que não expressavam o $P G C$, e apenas um óbito entre os 12 pacientes que produziam a proteína. Estes resultados sugerem que o PGC pode representar um novo fator de prognóstico favorável e um marcador de dependência androgênica nos pacientes com Cap.

Ademais, o valor diagnostico do PGC também já foi testado nos pacientes com Cap. Diamandis et al. (1997), desenvolveram anticorpos monoclonais contra o PGC em ratos e construíram um teste de dois-sítios tipo sanduíche com fluorometria como técnica de detecção. Eles não encontraram qualquer correlação entre a concentração sérica do PSA e do PGC em 44 pacientes com Cap analisados e, em contraste com nossa análise, concluíram que este marcador não é útil para o diagnóstico ou monitoramento do Cap. Para nosso conhecimento, o presente estudo representa a primeira análise na qual o PGC é descrito como um possível marcador diagnóstico no Cap. A relação da expressão do PGC com o estádio patológico revelou uma maior sub-expressão entre os pacientes com 
tumores T3 em relação aos T2 (figura 3), no entanto não houve diferença estatística de expressão de acordo com escore de Gleason (figura 5).

O PSMA é uma glicoproteína transmenbrana tipo 2 altamente expressa nas células do Cap e na neovasculatura de tumores sólidos não prostáticos (Ghosh e Heston, 2004). Como demonstrado por técnicas de Northern blot, Western blot ou imuno-histoquímica, o PSMA também é expresso em níveis mais baixos em outros tecidos, como a próstata normal, rim, fígado, intestino delgado, testículo, ovário, glândulas salivares, mama, musculatura esquelética e cérebro (Davis et al., 2005; Kinoshita et al., 2006). O PSMA pesa em torno de 100.000 daltons e possui um segmento intracelular (aminoácidos 1 a 18), um domínio transmembrana (aminoácidos 19 a 43), e um extenso domínio extracelular (aminoácidos 44 a 750). O gene do PSMA já foi clonado, seqüenciado e mapeado no cromossomo 11q11-12 (RinkerSchaeffer et al., 1995).

Por possuir estrutura semelhante a outras enzimas, o PSMA também é conhecido como glutamato carboxipeptidase 2, N-acetyl-a-linked acidic dipeptidase 1 (Naaladase 1), ou folato hidrolase 1. A folato hidrolase é ancorada na borda em escova do jejuno, e tem a função de hidrolisar o folato poliglutamilado em folato, permitindo assim sua absorção (Kinoshita et al., 2006). Ela também hidrolisa o $\mathrm{N}$-acetil-L-aspartil-L-Glutamato (atividade NAALADase), um neuropeptídeo presente de forma abundante no sistema nervoso central e periférico, que se liga ao receptor $\mathrm{N}$-metil-D-aspartato inibindo a liberação do glutamato e promovendo neuro-proteção. Portanto a hidrólise do N-acetil-L-aspartil-L-Glutamato permite a liberação de glutamato, 
um neurotransmissor mais potente que pode produzir uma degeneração progressiva e fatal de neurônios motores alvo, mecanismo implicado nos casos de esclerose lateral amiotrófica (Ghadge et al, 2003). O receptor $\mathrm{N}$ metil-D-aspartato também está presente na medula e está envolvido com mecanismos relacionado ao desenvolvimento da bexiga hiperativa após infarto cerebral (Yokoyama et al., 2004). A função fisiológica do PSMA nos demais órgãos além do sistema digestivo e nervoso ainda é desconhecida.

Em contraste com outros antígenos altamente restritos relacionados à próstata, como o PSA e a fosfatase ácida prostática, que são proteínas secretoras, o PSMA é integralmente uma proteína da membrana celular (Liu et al., 1998). Devido a esta característica, o PSMA tem sido explorado como marcador para detecção tumoral através de técnicas de imunoscintigrafia. $\mathrm{O}$ FDA (Food and Drug Administration) aprovou o anticorpo monoclonal 7E11 marcado com ${ }^{111}$ In (Prostascint, Cytogen, Princeton, NJ) contra o PSMA como método de imagem para diagnóstico do Cap. Este anticorpo se liga a um epítopo intracelular do PSMA exposto na morte celular. Rosenthal et al. (2001) avaliaram a utilidade do Prostascint no estadiamento de 631 pacientes com Cap de alto risco antes da linfadenectomia e demonstraram um valor preditivo positivo, negativo, sensibilidade e especificidade de $62 \%$, $72 \%, 62 \%$ e $72 \%$ respectivamente. O fato do anticorpo 7 E11 se ligar a um epítopo intracelular do PSMA representa uma desvantagem do método, desde que a ligação ocorre em áreas de necrose tumoral, que são incomuns nos sítios ósseos (Ghosh and Heston, 2004). 
Por outro lado, o domínio extracelular do PSMA é alvo de anticorpos monoclonais de segunda geração como o J591, que já são utilizado em estudos clínicos de fase 1 para distribuição específica de agentes de imagem ou com fins terapêuticos (anticorpos radio-conjugados) nas células que super-expressam o PSMA (Bander et al., 2003a). A habilidade do anticorpo monoclonal J591 em se ligar ao domínio extracelular do PSMA foi testada por Bander et al., (2003b) na análise de um estudo de fase 1 com o objetivo inicial de avaliar toxicidade, farmacocinética e dosimetria. Dos 42 pacientes elegíveis para o estudo, o J591 atingiu adequadamente as lesões ósseas em $94 \%$ dos casos e as lesões nas partes moles em $72 \%$ dos casos.

Apesar de sua função na carcinogênese prostática ainda ser desconhecida, vários estudos têm avaliado a expressão relativa do PSMA em pacientes com Cap em relação à pacientes com HPB ou mesmo com próstatas normais. Estudos utilizando imuno-histoquímica e outras técnicas demonstraram que apesar do PSMA estar expresso no tecido prostático normal, hiperplásico, na neoplasia intra-epitelial prostática e nos carcinomas invasivos, seu nível de expressão e atividade enzimática é maior neste último (Bostwick et al.,1998). Ademais, poucos anos após a descrição do $P S M A$, o mesmo grupo de pesquisadores descreveu uma molécula variante denominada PSM'. Estudos através da técnica de PCR demonstraram que enquanto a expressão do PSMA predomina sobre o $P S M^{\prime}$ no Cap, em próstatas normais ocorre uma predominância do PSM' sobre o PSMA (Su et al., 1995). Neste estudo, a expressão relativa dos dois genes foi expressa como um índice tumoral, definido pela razão PSMA/PSM'. Deste modo, o 
valor deste índice variou de 9 a 11 na linhagem celular LNCaP, de 3 a 6 no tecido de pacientes com Cap, de 0,75 a 1,6 na HPB e de 0,075 a 0,45 no tecido prostático normal. Da mesma forma como foi demonstrado em acima, na presente análise, a expressão tecidual do PSMA através do qRT-PCR no tecido tumoral foi sempre maior quando comparado ao tecido de pacientes com HPB. Da mesma forma, a expressão do PSMA pelas células do Cap aumenta com a progressão e desenvolvimento de metástases (Murphy et al., 2000)

Apesar de o PSMA estar habitualmente expresso de forma mais intensa no tecido prostático maligno e em pacientes que apresentam progressão e desenvolvimento de metástases (Murphy et al., 2000), alguns autores têm relatado uma diminuição de sua expressão tecidual nos tumores de alto grau. No estudo de kinoshita et al. (2006), que avaliou a expressão do PSMA em diversos tecidos por imuno-histoquímica, foi uma detectado uma imunorreatividade mais intensa com os anticorpos monoclonais $24.4 \mathrm{E} 6 \mathrm{e}$ 7E11.C5 nos tumores prostáticos de baixo grau. Contrariamente, na presente série, entre os 33 pacientes com Cap, 20 apresentaram escore de Gleason $\geq 7$, e estes casos apresentaram uma expressão estatisticamente semelhante aos pacientes com escore de Glason $<7$ (figura 9). Também não houve diferença estatística da expressão do PSMA entre os diferentes estádios patológicos (figura 7).

$\mathrm{Na}$ presente análise, quatro genes apresentaram uma expressão variável entre os tecidos malignos e benignos, não permitindo a diferenciação dos mesmos. Entre eles, o TMEFF2 (proteína transmembrana 
com domain EGF-like, e dois domains follistatin-like) cuja seqüencia semelhantes descrita (HPP1) tem mostrado diminuição da expressão da proteína no câncer colo-retal, principalmente por metilação (Sato et al., 2002), e no adenocarcinoma a partir do esôfago de Barret (Schulmann et al., 2005). O TMEFF2 também tem sido descrito como gene regulado pelos andrógenos e que possui capacidade de inibir o crescimento das células do Cap. Estudos tem demonstrado que o escape hormonal das células do Cap leva a uma redução da expressão deste gene, o que pode resultar em um comportamento mais agressivo (Gery et al., 2002). No presente estudo, o TMEFF2 esteve sub-expresso em $76 \%$ dos casos. Análise dos níveis de expressão do TMEFF2 de acordo com o estádio patológico e escore de Gleason através do teste de Mann-Whitney não revelaram diferença estatística (dados não demonstrados). O GREB1 (gene regulated in breast cancer 1) é um gene de resposta precoce ao estrógeno. Acredita-se que tenha um papel importante nos tecidos responsivos a hormônios e câncer. Relaciona-se com a expressão de receptor de estrógeno dos carcinomas de mama e a resposta as terapias endócrinas (Rae et al., 2005). Da mesma forma, estudos baseados na técnica de qRT-PCR tem demonstrado altos níveis de expressão desse gene em linhas celulares de HPB e Cap. O GREB1 também é regulado por andrógenos e a supressão deste gene pode bloquear o crescimento induzido pelos andrógenos, sugerindo que ele pode estar envolvido na proliferação do Cap (Rae et al., 2006). O TH1 (Trihydrophobin humana) é localizado no cromossomo 20q13, com transcrito de 2,4 kb. Proteína de função ainda não conhecida acredita-se ser um 
parceiro da A-Raf quinase, que pertence a via de transdução MAPK. São três isoformas, A-Raf, B-Raf e C-Raf, que de modo geral interagem com ativador Ras. Têm expressão diferente nos tecidos, sendo A-Raf distribuída predominantemente nos tecidos urogenitais. Estudos têm demonstrado que a expressão moderada de A-Raf é necessária para a progressão de G1 e proliferação celular. Liu et al. demonstraram a localização de A-Raf e TH1 e a provável ação inibidora de TH1 sobre A-Raf, podendo agir como um importante regulador do ciclo celular. (Liu et al., 2004). Nenhum estudo prévio relatou a expressão desse gene nas células do Cap e assim como o GREB1, sua expressão foi altamente variável no presente estudo. Finalmente a IGH3 (Human Ig gamma3) é uma imunoglobulina de cadeia pesada (Ig gamma). Proteinúria tem sido descrita em pacientes com Cap, à custa de cadeias leves e pesadas. A proteinúria leve é causada predominantemente por IgG gamma, principalmente em pacientes com câncer avançado. (Abdul e Hoosein, 1995). No presente estudo, a IGH3, de forma semelhante ao TMEFF2, esteve sub-expresso em $79 \%$ dos casos de Cap. Quando a expressão da $I G H 3$ foi avaliada de acordo com o estádio patológico e escore de Gleason através do teste de Mann-Whitney, não foi observado diferença estatística (dados não demonstrados).

Devido a sua grande sensibilidade, grande disponibilidade, e necessidade de apenas pequenas quantidades de RNA, o qRT-PCR revolucionou as técnicas de detecção de RNA e DNA. O qRT-PCR em tempo real, permite a detecção da amplificação do PCR durante as fases precoces da reação, o que representa uma grande vantagem em relação ao 
PCR convencional. Neste último, a utilização do gel de agarose só permite a detecção da ampliação do PCR no final da reação, o que consome tempo e pode durar até alguns dias. Ademais, no PCR convencional, a análise do nível de expressão gênica é baseada na discriminação do tamanho das bandas e, por isso, a análise quantitativa fica limitada. Finalmente, a resolução do gel de agarose é pobre (em torno de 10 vezes), enquanto que o qRT-PCR em tempo real pode detectar uma variação de apenas duas vezes na expressão gênica. Por esses motivos, o qRT-PCR vem sendo amplamente utilizado, entre outros métodos, para confirmação dos achados iniciais dos microarrays (Velasco et al., 2004).

Finalmente, algumas limitações do presente estudo merecem ser comentadas. O grupo controle foi constituído de pacientes com diagnóstico de HPB e não de pacientes com próstatas normais, sendo possível que a expressão dos seis genes estudados seja diferente entre próstatas normais e com hiperplasia. Apesar da obtenção de tecido prostático de pacientes com próstatas normais ser mais difícil, é necessário a confirmação destes achados neste grupo de indivíduos. Também é importante enfatizar que de acordo com o NCI-EDRN (National Cancer Institute Early Detection and Research Network), a presente análise representa um estudo pré-clínico de fase 1 (Pepe et al., 2001) e, portanto, fases adicionais e estandardizadas de avaliação e validação são necessárias para confirmação dos nossos resultados. 
Conclusão 


\section{CONCLUSÃO}

A combinação da super-expressão do $P S M A$ e sub-expressão do $P G C$ no tecido prostático pode representar uma evidência objetiva de presença de Cap. A manutenção desse padrão de expressão gênica no tecido prostático benigno de pacientes com câncer representa uma importante vantagem do método e pode solucionar a pouca sensibilidade da BTRUS no diagnóstico do Cap. 
Referências 


\section{REFERÊNCIAS}

Abdul M, Hoosein NM. Gammopathy associated with advanced prostate carcinoma. Urol Res. 1995;23:185-8.

Balbín M, López-Otín C. Hormonal regulation of the human pepsinogen $\mathrm{C}$ gene in breast cancer cells. Identification of a cis-acting element mediating its induction by androgens, glucocorticoids, and progesterone. J Biol Chem. 1996;271:15175-81.

Bander NH, Nanus DM, Milowsky MI, Kostakoglu L, Vallabahajosula S, Goldsmith SJ. Targeted systemic therapy of prostate cancer with a monoclonal antibody to prostate-specific membrane antigen. Semin Oncol. 2003a;30:667-76.

Bander NH, Trabulsi EJ, Kostakoglu L, Yao D, Vallabhajosula S, SmithJones P, Joyce MA, Milowsky M, Nanus DM, Goldsmith SJ. Targeting metastatic prostate cancer with radiolabeled monoclonal antibody J591 to the extracellular domain of prostate specific membrane antigen. J Urol. 2003b;170:1717-21.

Benson MC, Whang IS, Pantuck A, Ring K, Kaplan SA, Olsson CA, Cooner $\mathrm{WH}$. Prostate specific antigen density: a means of distinguishing benign prostatic hypertrophy and prostate cancer. J Urol. 1992;147:815-6.

Bostwick DG, Foster CS. Examination if radical prostatectomy specimens: Therapeutic and prognostic significance. Em: Pathology of Prostate; Foster e Bostwick, Editores. Series Major Problems in Pathology, Vol 34, pag 172, 1998. WB Saunders Company, Philadelphia, Pennsylvania, USA. 
Bostwick DG, Pacelli A, Blute M, Roche P, Murphy GP. Prostate specific membrane antigen expression in prostatic intraepithelial neoplasia and adenocarcinoma: a study of 184 cases. Cancer. 1998;82:2256-61.

Brasil. Ministério da Saúde. Instituto Nacional do Câncer. Estimativa de câncer 2008: prostata. [Acesso 12 jan 2008]. Disponível em: http://www.inca.gov.br/estimativa/2008/

Carter HB, Pearson JD, Metter EJ, Brant LJ, Chan DW, Andres R, Fozard JL, Walsh PC. Longitudinal evaluation of prostate-specific antigen levels in men with and without prostate disease. JAMA. 1992;267:2215-20.

Catalona WJ, Richie JP, Ahmann FR, Hudson MA, Scardino PT, Flanigan RC, deKernion JB, Ratliff TL, Kavoussi LR, Dalkin BL, et al. Comparison of digital rectal examination and serum prostate specific antigen in the early detection of prostate cancer: results of a multicenter clinical trial of 6,630 men. J Urol. 1994;151:1283-90.

Davis MI, Bennett MJ, Thomas LM, Bjorkman PJ. Crystal structure of prostate-specific membrane antigen, a tumor marker and peptidase. Proc Natl Acad Sci U S A. 2005;102:5981-6.

de Kok JB, Verhaegh GW, Roelofs RW, Hessels D, Kiemeney LA, Aalders TW, Swinkels DW, Schalken JA. DD3(PCA3), a very sensitive and specific marker to detect prostate tumors. Cancer Res. 2002 ;62:2695-8.

Diamandis EP, Nadkarni S, Bhaumik B, Abdelrahman A, Melegos DN, Borchert G, Black MH, Alonso M, Salas A, de los Toyos JR, Sampedro A, López-Otín C. Immunofluorometric assay of pepsinogen $C$ and preliminary clinical applications. Clin Chem. 1997;43:1365-71. 
Díaz M, Rodríguez JC, Sánchez J, Sánchez MT, Martín A, Merino AM, Vizoso F. Clinical significance of pepsinogen $C$ tumor expression in patients with stage D2 prostate carcinoma. Int J Biol Markers. 2002;17:125-9.

Djavan B, Zlotta A, Remzi M, Ghawidel K, Basharkhah A, Schulman CC, Marberger M. Optimal predictors of prostate cancer on repeat prostate biopsy: a prospective study of 1,051 men. J Urol. 2000; 163:1144-8

Frauscher F, Klauser A, Volgger H, Halpern EJ, Pallwein L, Steiner H, Schuster A, Horninger W, Rogatsch H, Bartsch G. Comparison of contrast enhanced color Doppler targeted biopsy with conventional systematic biopsy: impact on prostate cancer detection. J Urol. 2002;167:1648-52.

Gery S, Sawyers CL, Agus DB, Said JW, Koeffler HP. TMEFF2 is an androgen-regulated gene exhibiting antiproliferative effects in prostate cancer cells. Oncogene. 2002;21:4739-46.

Ghadge GD, Slusher BS, Bodner A, Canto MD, Wozniak K, Thomas AG, Rojas C, Tsukamoto T, Majer P, Miller RJ, Monti AL, Roos RP. Glutamate carboxypeptidase II inhibition protects motor neurons from death in familial amyotrophic lateral sclerosis models. Proc Natl Acad Sci U $S$ A. 2003;100:9554-9.

Ghosh A, Heston WD. Tumor target prostate specific membrane antigen (PSMA) and its regulation in prostate cancer. J Cell Biochem. 2004;91:52839.

Gleason DF: Histologic grading of prostate cancer: A perspective. Hum Pathol, 1992; 23:273-279. 
Haas GP, Delongchamps NB, Jones RF, Chandan V, Serio AM, Vickers AJ, Jumbelic M, Threatte G, Korets R, Lilja H, de la Roza G. Needle biopsies on autopsy prostates: sensitivity of cancer detection based on true prevalence. $J$ Natl Cancer Inst. 2007;99:1484-9.

Hara N, Kasahara T, Kawasaki T, Bilim V, Obara K, Takahashi K, Tomita Y. Reverse transcription-polymerase chain reaction detection of prostatespecific antigen, prostate-specific membrane antigen, and prostate stem cell antigen in one milliliter of peripheral blood: value for the staging of prostate cancer. Clin Cancer Res. 2002;8:1794-9.

Harden SV, Sanderson H, Goodman SN, Partin AA, Walsh PC, Epstein JI, Sidransky D. Quantitative GSTP1 methylation and the detection of prostate adenocarcinoma in sextant biopsies. J Natl Cancer Inst. 2003;95:1634-7.

Humphrey PA, Vollmer RT: Intraglandular tumor extent and prognosis in prostatic carcinoma: aplication of a grid method to prostatectomy specimens. Hum Pathol 1990; 21:799-804.

International Union Against Cancer (UICC): TNM Classification of malignant tumours, 6th ed, Sobin LH, Wittekind Ch (ed.), New York, Wiley-Liss. 2002; pp. 184-7.

Jemal A, Siegel R, Ward E, Hao Y, Xu J, Murray T, Thun MJ. Cancer statistics, 2008. CA Cancer J Clin. 2008;58:71-96.

Jovanovic BD, Bergan RC, Kibbe WA. Some aspects of analysis of gene array data. Cancer Treat Res. 2002;113:71-89.

Kinoshita Y, Kuratsukuri K, Landas S, Imaida K, Rovito PM Jr, Wang CY, Haas GP. Expression of prostate-specific membrane antigen in normal and malignant human tissues. World J Surg. 2006;30:628-36. 
Konishi N, Nakaoka S, Matsumoto K, Nakamura M, Kuwashima S, Hiasa Y, Cho M, Uemura H, Hirao Y. Expression of pepsinogen II with androgen and estrogen receptors in human prostate carcinoma. Pathol Int. 1999;49:203-7.

Liu H, Rajasekaran AK, Moy P, Xia Y, Kim S, Navarro V, Rahmati R, Bander $\mathrm{NH}$. Constitutive and antibody-induced internalization of prostate-specific membrane antigen. Cancer Res. 1998;58:4055-60.

Liu HJ, Guo XL, Dong M, Wang L, Yuan Y. Association between pepsinogen $\mathrm{C}$ gene polymorphism and genetic predisposition to gastric cancer. World $\mathrm{J}$ Gastroenterol. 2003;9:50-3.

Liu W, Shen X, Yang Y, Yin X, Xie J, Yan J, Jiang J, Liu W, Wang H, Sun M, Zheng $Y, G u$ J. Trihydrophobin 1 is a new negative regulator of A-Raf kinase. J Biol Chem. 2004;279:10167-75.

Livak KJ, Schmittgen TD. Analysis of relative gene expression data using real-time quantitative PCR and the 2(-Delta Delta $\mathrm{C}(\mathrm{T})$ ) Method. Methods. 2001;25:402-8.

Magee JA, Araki T, Patil S, Ehrig T, True L, Humphrey PA, Catalona WJ, Watson MA, Milbrandt J. Expression profiling reveals hepsin overexpression in prostate cancer. Cancer Res. 2001;61:5692-6.

Murphy GP, Snow PB, Brandt J, Elgamal A, Brawer MK. Evaluation of prostate cancer patients receiving multiple staging tests, including ProstaScint scintiscans. Prostate. 2000;42:145-9.

Oesterling JE, Jacobsen SJ, Chute CG, Guess HA, Girman CJ, Panser LA, Lieber MM. Serum prostate-specific antigen in a community-based 
population of healthy men. Establishment of age-specific reference ranges. JAMA. 1993;270:860-4.

Patel K, Whelan PJ, Prescott S, Brownhill SC, Johnston CF, Selby PJ, Burchill AS. The use of real-time reverse transcription-PCR for prostatespecific antigen mRNA to discriminate between blood samples from healthy volunteers and from patients with metastatic prostate câncer. Clin Cancer Res 2004;10:7511-19.

Parekh DJ, Ankerst DP, Troyer D, Srivastava S, Thompson IM. Biomarkers for prostate cancer detection. J Urol. 2007;178:2252-9.

Partin AW, Catalona WJ, Southwick PC, Subong EN, Gasior GH, Chan DW. Analysis of percent free prostate-specific antigen (PSA) for prostate cancer detection: influence of total PSA, prostate volume, and age. Urology. 1996;48:55-61.

Pepe MS, Etzioni R, Feng Z, Potter JD, Thompson ML, Thornquist M, Winget $\mathrm{M}$, Yasui $\mathrm{Y}$. Phases of biomarker development for early detection of cancer. $\mathrm{J}$ Natl Cancer Inst. 2001;93:1054-61.

Rae JM, Johnson MD, Scheys JO, Cordero KE, Larios JM, Lippman ME. GREB 1 is a critical regulator of hormone dependent breast cancer growth. Breast Cancer Res Treat. 2005;92:141-9.

Rae JM, Johnson MD, Cordero KE, Scheys JO, Larios JM, Gottardis MM, Pienta KJ, Lippman ME. GREB1 is a novel androgen-regulated gene required for prostate cancer growth. Prostate. 2006;66:886-94.

Reese JH, McNeal JE, Redwine EA, Samloff IM, Stamey TA. Differential distribution of pepsinogen II between the zones of the human prostate and the seminal vesicle. J Urol. 1986;136:1148-52. 
Rinker-Schaeffer CW, Hawkins AL, Su SL, Israeli RS, Griffin CA, Isaacs JT, Heston WD. Localization and physical mapping of the prostate-specific membrane antigen (PSM) gene to human chromosome 11. Genomics. 1995;30:105-8.

Rosenthal SA, Haseman MK, Polascik TJ. Utility of capromab pendetide (ProstaScint) imaging in the management of prostate cancer. Tech Urol. 2001;7:27-37.

Rubin MA, Zhou M, Dhanasekaran SM, Varambally S, Barrette TR, Sanda MG, Pienta KJ, Ghosh D, Chinnaiyan AM. alpha-Methylacyl coenzyme A racemase as a tissue biomarker for prostate cancer. JAMA. 2002;287:166270.

Sánchez LM, Freije JP, Merino AM, Vizoso F, Foltmann B, López-Otín C. Isolation and characterization of a pepsin $\mathrm{C}$ zymogen produced by human breast tissues. J Biol Chem. 1992;267:24725-31.

Sato F, Shibata D, Harpaz N, Xu Y, Yin J, Mori Y, Wang S, Olaru A, Deacu E, Selaru FM, Kimos MC, Hytiroglou P, Young J, Leggett B, Gazdar AF, Toyooka S, Abraham JM, Meltzer SJ. Aberrant methylation of the HPP1 gene in ulcerative colitis-associated colorectal carcinoma. Cancer Res. 2002;62:6820-2.

Schalken JA, Bergh A, Bono A, Foster C, Gospadarowicz M, Isaacs WB, Rubin M, Schroder F, Tribukait B, Tsukamotot T, Wiklund P. Molecular prostate cancer pathology: current issues and achievements. Scand J Urol Nephrol Suppl. 2005; (216):82-93.

Schmid HP. Tumour markers in patients on deferred treatment: prostate specific antigen doubling times. Cancer Surv. 1995;23:157-67. 
Schulmann K, Sterian A, Berki A, Yin J, Sato F, Xu Y, Olaru A, Wang S, Mori Y, Deacu E, Hamilton J, Kan T, Krasna MJ, Beer DG, Pepe MS, Abraham JM, Feng Z, Schmiegel W, Greenwald BD, Meltzer SJ. Inactivation of p16, RUNX3, and HPP1 occurs early in Barrett's-associated neoplastic progression and predicts progression risk. Oncogene. 2005;24:4138-48.

Serra Díaz C, Vizoso F, Rodríguez JC, Merino AM, González LO, Baltasar A, Pérez-Vázquez MT, Medrano J. Expression of pepsinogen $\mathrm{C}$ in gynecomastias and male breast carcinomas. World J Surg. 1999;23:439-45.

Srougi M, Dall'oglio MF, Bomfim AC, Andreoni C, Cury J, Ortiz V. An improved technique for controlling bleeding during simple retropubic prostatectomy. BJU Int. 2003;92:813-7.

Su SL, Huang IP, Fair WR, Powell CT, Heston WD. Alternatively spliced variants of prostate-specific membrane antigen RNA: ratio of expression as a potential measurement of progression. Cancer Res. 1995;55:1441-3.

Thompson IM, Pauler DK, Goodman PJ, Tangen CM, Lucia MS, Parnes HL, Minasian LM, Ford LG, Lippman SM, Crawford ED, Crowley JJ, Coltman CA Jr. Prevalence of prostate cancer among men with a prostate-specific antigen level < or =4.0 ng per milliliter. N Engl J Med. 2004;350:2239-46.

Velasco AM, Gillis KA, Li Y, Brown EL, Sadler TM, Achilleos M, Greenberger LM, Frost $P$, Bai W, Zhang $Y$. Identification and validation of novel androgenregulated genes in prostate cancer. Endocrinology. 2004;145:3913-24.

Vizoso F, Sánchez LM, Díez-Itza I, Merino AM, López-Otín C. Pepsinogen C is a new prognostic marker in primary breast cancer. $\mathrm{J}$ Clin Oncol. 1995;13:54-61. 
Wang MC, Valenzuela LA, Murphy GP, Chu TM. Purification of a human prostate specific antigen. Invest Urol 1979;17:159.

Welch HG, Fisher ES, Gottlieb DJ, Barry MJ. Detection of prostate cancer via biopsy in the Medicare-SEER population during the PSA era. J Natl Cancer Inst. 2007;99:1395-400.

Yokoyama O, Mizuno H, Komatsu K, Akino H, Tanase K, Namiki M. Role of glutamate receptors in the development and maintenance of bladder overactivity after cerebral infarction in the rat. J Urol. 2004;171:1709-14.

Yuen JS, Thng CH, Tan PH, Khin LW, Phee SJ, Xiao D, Lau WK, Ng WS, Cheng CW. Endorectal magnetic resonance imaging and spectroscopy for the detection of tumor foci in men with prior negative transrectal ultrasound prostate biopsy. J Urol. 2004;171:1482-6. 